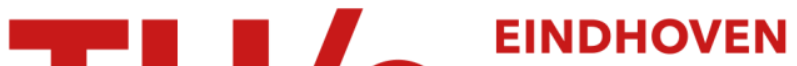

\section{A DNS study of flow and heat transfer through slender fixed- bed reactors randomly packed with spherical particles}

\section{Citation for published version (APA):}

Das, S., Deen, N. G., \& Kuipers, J. A. M. (2017). A DNS study of flow and heat transfer through slender fixedbed reactors randomly packed with spherical particles. Chemical Engineering Science, 160, 1-19.

https://doi.org/10.1016/j.ces.2016.11.008

\section{Document license:}

TAVERNE

DOI:

10.1016/j.ces.2016.11.008

Document status and date:

Published: 16/03/2017

\section{Document Version:}

Publisher's PDF, also known as Version of Record (includes final page, issue and volume numbers)

\section{Please check the document version of this publication:}

- A submitted manuscript is the version of the article upon submission and before peer-review. There can be important differences between the submitted version and the official published version of record. People interested in the research are advised to contact the author for the final version of the publication, or visit the $\mathrm{DOI}$ to the publisher's website.

- The final author version and the galley proof are versions of the publication after peer review.

- The final published version features the final layout of the paper including the volume, issue and page numbers.

Link to publication

\section{General rights}

Copyright and moral rights for the publications made accessible in the public portal are retained by the authors and/or other copyright owners and it is a condition of accessing publications that users recognise and abide by the legal requirements associated with these rights.

- Users may download and print one copy of any publication from the public portal for the purpose of private study or research.

- You may not further distribute the material or use it for any profit-making activity or commercial gain

- You may freely distribute the URL identifying the publication in the public portal.

If the publication is distributed under the terms of Article 25fa of the Dutch Copyright Act, indicated by the "Taverne" license above, please follow below link for the End User Agreement:

www.tue.nl/taverne

Take down policy

If you believe that this document breaches copyright please contact us at:

openaccess@tue.nl

providing details and we will investigate your claim. 


\title{
A DNS study of flow and heat transfer through slender fixed-bed reactors randomly packed with spherical particles
}

\author{
Saurish Das ${ }^{\mathrm{a}}$, Niels G. Deen ${ }^{\mathrm{b}, *}$, J.A.M. Kuipers ${ }^{\mathrm{a}}$ \\ a Multiphase Reactors Group, Department of Chemical Engineering and Chemistry, Eindhoven University of Technology, P.O. Box 513, 5600 MB Eindhoven, \\ The Netherlands \\ b Multiphase and Reactive Flows Group, Department of Mechanical Engineering, Eindhoven University of Technology, P.O. Box 513, 5600 MB Eindhoven, \\ The Netherlands
}

\section{A R T I C L E I N F O}

\section{Keywords:}

Packed bed

Random packing

Direct numerical simulation (DNS)

Discrete element method (DEM)

Immersed boundary method (IBM)

Conjugate heat transfer (CHT)

\begin{abstract}
A B S T R A C T
A fully resolved direct numerical simulation of flow and heat transfer is presented for slender randomly packed bed reactors. The flow and temperature field are solved over a non-body fitted, non-conformal Cartesian computational domain. The coupling between fluid and solid (both spherical particles and cylindrical wall) is enforced by a second order accurate, sharp interface immersed boundary method (IBM). The present numerical technique neither requires any challenging volumetric mesh generation process nor demands manipulation of the geometry near the particle-particle and particle-wall contact points. Conjugate heat transfer has been considered where the temperature field is calculated both inside the solid particles and in the fluid. A discrete element method (DEM) is used to generate the random packings of spherical particles in the cylindrical column, and a methodology is proposed to calculate the radial porosity profile of the bed.

The column-to-particle diameter ratio $(N)$ is varied from 4 to 8 , and two separate cases have been considered where $N \rightarrow \infty$. The particle Reynolds number $\left(R e_{d}\right)$ is varied from 1 to 500 . The numerically obtained pressure drop and overall wall-to-bed heat transfer coefficient for different simulation cases are critically compared with empirical correlations and a good agreement is reported. Moreover, based on the current numerical results, correlations are proposed for the pressure drop and the wall-to-bed heat transfer coefficient. The effect of the column-to-particle diameter ratio $(N)$ on both the flow and heat transfer, as-well-as the effect of the solid to fluid thermal conductivity ratio on the conjugate heat transfer are discussed. Furthermore, the fully resolved accurate numerical simulations have helped to elucidate the detailed pore-scale flow and heat transfer feature in the packed beds.
\end{abstract}

\section{Introduction}

Catalytic tubular fixed bed reactors are the most common and important type of reactors in the chemical and process industries. The reactions take place at the surface of catalysts particles (heterogeneous reaction) and most of the time these reactions are exothermic. Minimizing the overall pressure drop, temperature control, and species conversion rates are the key criteria for the design of such reactors. The pressure drop is directly related to the power requirements of the supplying pump and temperature control is important for the environmental safety as-well-as the performance of the catalyst. Usually, the reaction rate, and thus the rate of heat production is an exponential function of the operating temperature. If no proper cooling is applied, the reactor temperature will increase very rapidly along the length of the reactor, which may result in damaging of the catalyst. If the cooling rate is insufficient, more and more reactants will be consumed and the accompanying rapid temperature rise can lead to a thermal runaway scenario. In general, the reactors are operated close to this runaway condition as to maximize the yield and to minimize the reactor size. Consequently, they become very sensitive to the operating conditions. Any small change may lead to catastrophic failure and hence, a precise knowledge of heat and mass transfer characteristics of such reactors is crucial. The highest selectivity can be achieved when the temperature change across the volume of the reactor is minimal. As a result, industrial multi-tubular packed bed reactors are very popular, because they consist of a large number of parallel tubes, placed inside a cooling jacket. The diameter of the individual reactor tubes is small, in the same order as the catalysts particle diameter, to offer a high specific heat transfer surface area. Boiling water is often preferred as a heat transfer medium outside the tube, which offers a high (external) heat transfer coefficient, and it also provides a constant temperature over the entire cooling jacket.

\footnotetext{
* Corresponding author.
} 
Several simplified, coarse-grained numerical models are used in design process of industrial reactors. In the macro description of packed beds, the solid and liquid phases are treated as continua, leading to a single mixture (homogeneous macro model) or two separate mixtures (heterogeneous macro model) with effective properties. Volume averaged transport equations are solved and these models are valid with fairly simplified assumptions, like homogeneity, axisymmetric particle distribution, effective transport parameters etc. Despite that local flow features are neglected, it can provide a fairly good description of the global flow and transport phenomena using accurate closures for effective transport parameters. For instance, transport through a large column can be predicted by a 2D axisymmetric model, which requires, (i) a radial porosity profile to account for in homogeneities near the wall, (ii) a drag closure for momentum transfer between the solid and liquid phases, (iii) an effective radial (axial) thermal conductivity to account for the micro-mechanism of heat transfer in radial (axial) direction, (iv) a wall-to-bed heat transfer coefficient, to model the increased resistance near the wall. In the next level of volume averaging or homogenization, a phenomenological model for packed beds characterizes the full bed by one or two (i.e. near-wall-region and core-region) bulk porosities. Both the macromodels and the phenomenological model require closures for effective transport, which can only be obtained through either experiments or computationally expensive fully resolved numerical simulations. Also, for very slender columns wall effect results in an inhomogeneous porosity distribution, which poses a major problem for coarse-grained models of slender columns. Hence, fully resolved simulations are often required. The interested reader may refer to several contributions by Dixon (2012), Dixon and Nijemeisland (2001) which shows the use of closures from fully resolved simulation in macroscopic models for packed bed.

In this paper, we study the flow and heat transfer through slender packed bed reactors by means of an accurate, assumption free, fully resolved 3-D CFD numerical model. The analysis of transport phenomena through packed bed reactors constitutes a classical problem. Though numerous attempts have been undertaken to experimentally study the packed bed reactors, only a very few and limited fully resolved direct numerical simulations (DNS) have been performed. The random packing of the particles in the bed leads to a very complex flow pattern in the interstitial space between the particles. This requires a sophisticated meshing technique, especially for the regions around particle-particle and particle-wall contacts Dixon et al. (2013). Furthermore, the generation of random packings, computational expenses, and proper particle-particle, as-well-as particle-wall boundary treatments make this problem numerically very challenging. Almost all the authors have utilized unstructured body-fitted grids to fully resolve the particles and the cylindrical wall. To generate random packings, they have used discrete element method (DEM). It requires exporting particle locations to a meshing software in order to generate a 3D volumetric mesh. A summary of previous CFD modeling studies of the hydrodynamics and heat transfer in packed beds is presented in Table 1. Please note that the ratio of the column diameter $(D)$ to particle diameter $(d)$ is represented by $N$ and the Reynolds number $\left(R e_{d}\right)$ is calculated based on the particle diameter $(d)$.

By closely looking into the cited literature the following conclusions can be drawn:

- For 3D numerical study, volumetric mesh generation for the fluid zone inside the packed beds is a challenge due to infinitesimal small particle-particle and particle-wall contact area. Several meshing strategies (e.g. creating gaps or overlaps or bridges or caps between the two contacting particles) have been explored to avoid highly skewed computational cells near the particle-particle and particlewall contact area.

- Most of the numerical studies employed the Reynolds-averaged Navier-Stokes (RANS) equations without properly resolving the
Table 1

Summary of previous CFD modeling studies of hydrodynamics and heat transfer in packed beds; $N=D / d$ is the column-to-particle diameter ratio and $R e_{d}$ is the particle Reynolds number.

\begin{tabular}{|c|c|c|c|}
\hline Reference & Domain size and shape & Numerical model & $\begin{array}{l}R e_{d} \\
\text { range }\end{array}$ \\
\hline $\begin{array}{c}\text { Dixon et al. } \\
(2012)\end{array}$ & $\begin{array}{l}\text { Random packing of } \\
\text { spheres in a cylindrical } \\
\text { column; } N=5.45 \text { and } \\
7.44\end{array}$ & $\begin{array}{l}\text { Standard } k-\varepsilon \text { turbulent } \\
\text { model for both flow and } \\
\text { energy; temperature inside } \\
\text { the solid is also solved. }\end{array}$ & $\begin{array}{l}1600 \text { to } \\
27,000\end{array}$ \\
\hline $\begin{array}{l}\text { Tabib et al. } \\
\text { (2013) }\end{array}$ & $\begin{array}{l}\text { Spheres, cylinders and } \\
\text { fluted rings are } \\
\text { randomly packed in a } \\
\text { cylindrical column; } \\
N=2,2.5,3 \text { and } 15\end{array}$ & $\begin{array}{l}\text { Realizable } k-\varepsilon \text { turbulent } \\
\text { model for both flow and } \\
\text { heat transfer; a constant } \\
\text { wall temperature is } \\
\text { specified at the particle } \\
\text { surfaces. }\end{array}$ & $\begin{array}{l}\text { up-to } \\
1600\end{array}$ \\
\hline $\begin{array}{l}\text { Bai et al. } \\
\text { (2009) }\end{array}$ & $\begin{array}{l}\text { Structured and random } \\
\text { packing of spherical and } \\
\text { cylindrical particles in } \\
\text { cylindrical and } \\
\text { rectangular columns; } \\
N<4\end{array}$ & $\begin{array}{l}\text { Only flow field is studied } \\
\text { using standard } k-\varepsilon \\
\text { turbulent model. }\end{array}$ & $\begin{array}{l}2000 \text { to } \\
20,000\end{array}$ \\
\hline $\begin{array}{l}\text { Eppinger } \\
\text { et al. } \\
\text { (2011) }\end{array}$ & $\begin{array}{l}\text { Random packing of } \\
\text { sphere in a cylindrical } \\
\text { column; } 3 \leq N \leq 10\end{array}$ & $\begin{array}{l}\text { Only flow field is studied } \\
\text { using standard } k-\varepsilon \\
\text { turbulent model. }\end{array}$ & $\begin{array}{l}\text { up-to } \\
1000\end{array}$ \\
\hline $\begin{array}{l}\text { Ookawara } \\
\text { et al. } \\
\text { (2007) }\end{array}$ & $\begin{array}{l}\text { Random packing of } \\
\text { sphere in a cylindrical } \\
\text { column; } 4 \leq N \leq 8\end{array}$ & $\begin{array}{l}\text { DNS for both flow and } \\
\text { energy in an unstructured } \\
\text { mesh; a constant wall } \\
\text { temperature is specified at } \\
\text { the particle surfaces. }\end{array}$ & $\begin{array}{l}\text { up-to } \\
510\end{array}$ \\
\hline $\begin{array}{l}\text { Atmakidis } \\
\text { and Kenig } \\
(2009)\end{array}$ & $\begin{array}{l}\text { Random packing of } \\
\text { sphere in a cylindrical } \\
\text { column; } N=2,3,5 \text { and } 7\end{array}$ & $\begin{array}{l}\text { DNS for only } \\
\text { hydrodynamics in an } \\
\text { unstructured mesh. }\end{array}$ & $\begin{array}{l}\text { up-to } \\
100\end{array}$ \\
\hline $\begin{array}{l}\text { Riefler et al. } \\
\quad(2012)\end{array}$ & $\begin{array}{l}\text { Randomly placed } \\
\text { sphere in a cylindrical } \\
\text { confined; } N=6.44\end{array}$ & $\begin{array}{l}\text { DNS for only } \\
\text { hydrodynamics in an } \\
\text { unstructured mesh. }\end{array}$ & up-to 30 \\
\hline $\begin{array}{l}\text { Boccardo } \\
\text { et al. } \\
\text { (2015) }\end{array}$ & $\begin{array}{l}\text { Bi-disperse and mono- } \\
\text { disperse spherical } \\
\text { particles, cylindrical } \\
\text { particles and trilobes } \\
\text { are randomly packed in } \\
\text { a large cylindrical } \\
\text { column. }\end{array}$ & $\begin{array}{l}\text { DNS for only } \\
\text { hydrodynamics in an } \\
\text { unstructured mesh. }\end{array}$ & $\begin{array}{l}\text { up-to } \\
120\end{array}$ \\
\hline $\begin{array}{l}\text { Maier et al. } \\
\text { (1998) }\end{array}$ & $\begin{array}{l}\text { Cylindrical and } \\
\text { rectangular columns are } \\
\text { randomly filled with } \\
\text { spherical particles. } \\
N=6.72,7.23,9.62 \text { and } \\
10.7\end{array}$ & $\begin{array}{l}\text { Lattice Boltzmann Method } \\
\text { (LBM) is used to fully } \\
\text { resolve flow in a Cartesian } \\
\text { computational domain. }\end{array}$ & up-to 30 \\
\hline
\end{tabular}

boundary layers at the particle surfaces. These methods are not free from empiricism and use of so-called turbulent wall function treatment in a highly tortuous flow through porous structure is debatable.

- Numerical results for a limited range of column-to-particle diameter ratios are available, hence no correlation for bulk quantities like fully developed pressure drop and wall-to-bed heat transfer based on numerical studies have been proposed.

- The dependency of the heat transfer rate on the column-to-particle diameter ratio is yet to be quantified by means of accurate numerical simulation. The effect of solid (particle) conductivity on the overall wall-to-bed heat transfer coefficient needs to be evaluated as well. To study this effect the temperature needs to be solved in both the solid and fluid zones, i.e. a conjugate heat transfer model is required.

To avoid the tedious mesh generation process, as-well-as to avoid geometrical manipulation in the particle-particle contact points, in the present study, a second order accurate implicit immersed boundary method (IBM) has been used to fully resolve the solid wall in a nonbody conforming Cartesian computational grid. Both solid particles and the cylindrical column wall have been resolved as immersed boundaries, and the temperature inside the solid is also solved by a 
conjugate heat transfer (CHT) model. Details of the numerical model, implementation and validation can be found in Das et al. (2016a, 2016b). The column-to-particle diameter ratio, $N$ is varied from 4 to 8 and the particle Reynolds number $\left(R e_{d}\right)$ is varied from 1 to 500 . The packing is also generated for cases with $N=12$ and 16 , and only the central core section of these latter two cases is considered for simulation as to mimic a system without wall effects, i.e. for $N \rightarrow \infty$. A discrete element model (DEM) for particulate simulations has been used to create a random packing in a cylindrical column. After generating the packings for different cases, we import the particle locations into our in-house immersed boundary method (IBM) based CFD code.

In this paper, we will first briefly discuss the numerical methodology and analysis techniques. Subsequently, we report the bulk porosity and radial porosity profile for different column-particle combinations. The flow structure and temperature variation at the pore-scale level are shown. Non-dimensional pressure drops and wall-to-bed heat transfer coefficients for different cases are then reported. The effect of the solid conductivity on the conjugate heat transfer is presented next. Finally, a pressure drop correlation and correlation for wall-to-bed heat transfer coefficient are proposed.

\section{Numerical methodology}

\subsection{Flow and heat transfer modeling by immersed boundary method} (IBM)

The conservation equations for mass, momentum and energy are solved over a 3D Cartesian domain. For the present heat transfer analysis, the energy equations are solved for both the fluid and solid phases satisfying the continuity of temperature and heat flux at the fluid-solid interface (conjugate heat transfer). The following governing equations are solved:

$\nabla \cdot \bar{u}=0$

$\rho_{f} \frac{\partial \bar{u}}{\partial t}+\rho_{f} \nabla \cdot(\bar{u} \bar{u})=-\nabla p+\mu \nabla^{2} \bar{u}$

fluid phase: $\rho_{f} C_{p f} \frac{\partial T_{f}}{\partial t}+\rho_{f} C_{p f} \bar{u} \cdot \nabla T=k_{f} \nabla^{2} T_{f}$

solid phase: $\rho_{s} C_{p s} \frac{\partial T_{s}}{\partial t}=k_{s} \nabla^{2} T_{s}$

Sub-scripts ' $s$ ' and ' $f$ represent solid and fluid respectively, $\bar{u}$ is the velocity vector; $\rho, \mu, C_{p}$ and $k$ are the density, viscosity, specific heat and thermal conductivity respectively. In the current finite-volume implementation the transport equations are integrated on a staggered (Cartesian) computational mesh. The fluid-solid interface does not confirm the Cartesian grids and to accurately incorporate the solidfluid coupling for both momentum and energy an immersed boundary method (IBM) is used. At the solid-fluid interface, it ensures i) no-slip condition for the velocity; and ii) continuity of heat flux and temperature between the solid and fluid phases. Details of the numerical model, implementation and validation can be found in Das et al. (2016a, 2016b). However, in the consequent paragraphs, the in-house IBMCHT model is briefly discussed.

The implementation of the present immersed boundary method (IBM) in a Cartesian computational domain, schematically shown in the Fig. 1. To enforce boundary condition for flow and heat transfer at the impermeable wall, at first all the cells are marked/ flagged as either "solid-cell" (cell-center inside the solid body) or "fluid-cell"(cell-center in the fluid zone) in staggered computational grid. The algebraic form of the discretized momentum or energy equation at any cell-center ' $c$ ' (solid or fluid) can be represented as,

$a_{c} \phi_{c}+\sum_{n b} a_{n b} \phi_{n b}=b_{c}$

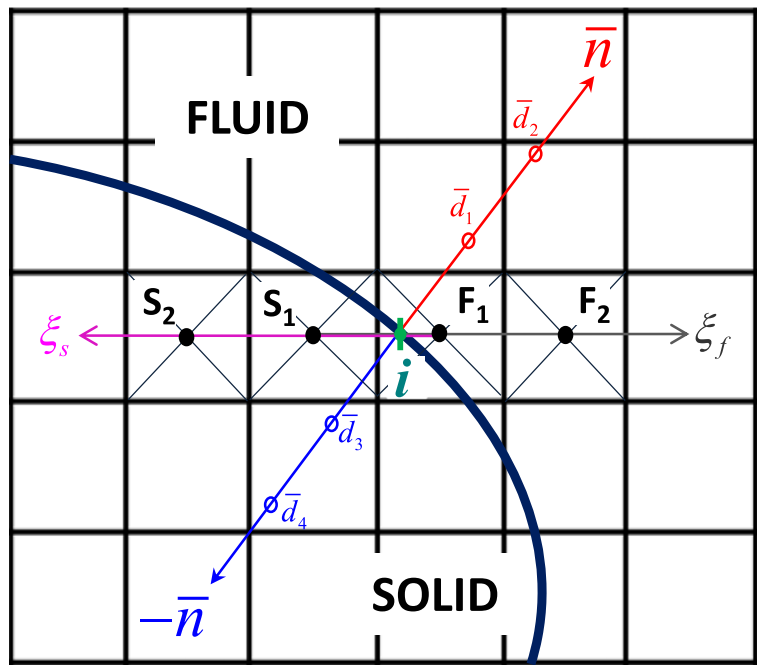

Fig. 1. The implementation of conjugate heat transfer (CHT) model in a Cartesian computational domain.

where $\phi$ corresponds to one of the fluid velocity components or temperature, and ' $n b$ ' indicates the cell-center of surrounding neighboring cells. ' $a$ ' represents the fluid property and geometry dependent neighboring coefficients and all the explicit terms are summed in $b_{c}$. For a perspective of a fluid-cell (solid-cell) ' $c$ ', if one of the surrounding cells ' $n b$ ' represent solid-cell (fluid-cell), the specific boundary condition (no-slip and temperature Dirichlet condition) is imposed by changing the central coefficient $\left(a_{c}\right)$ and neighboring coefficient $\left(a_{n b}\right)$ of Eq. (5), detailed in Das et al. (2016a, 2016b). For momentum, all the solid-cells are set to zero velocity $\left(a_{c}=1, a_{n b}=0, b_{c}=0\right)$, however for conjugate heat transfer (CHT) analysis, energy Eq. (4) needs to be solved in all the solid-cells as well. Solid thermal properties are assigned for the solid-cells and along with this for the present sharp interface IBM we enforce continuity of the temperature and the normal heat flux at the solid-fluid interface ('i), i.e.

$\mathrm{T}_{f} \mathrm{l}_{i}=\mathrm{T}_{s} l_{i} \quad$ and $\quad-\mathrm{k}_{f} \frac{\partial \mathrm{T}_{f}}{\partial \overline{\mathrm{n}}} \mathrm{I}_{i}=-\left.\mathrm{k}_{s} \frac{\partial \mathrm{T}_{s}}{\partial \overline{\mathrm{n}}}\right|_{i}$

In Fig. $1, F_{1}$ and $F_{2}$ are the two fluid cells, and $S_{1}$ and $S_{2}$ are the two solid cells. $\bar{n}$ in the normal at the interface, and $i$ is the intersection of the grid-line $(\xi)$ with the fluid-solid interface. In the current CHT implementation, using Eq. (6), the temperature at the fluid-solid interface, $T_{i}$, is calculated from the previous time-step temperature field, and in the current time-step used as a boundary condition for the shared immersed boundary between fluid and solid. As a results, fluid and solid cells are get decoupled, which separately satisfy Eq. (6) at the interface. For all the near boundary cells $\left(T_{i}\right)$ is calculate by Taylor series expansion of Eq. (6) in the normal direction $(\bar{n})$. To facilitate a second order scheme, four probes - two in the fluid $\left(\overline{d_{1}}\right.$ and $\left.\overline{d_{2}}\right)$ and two in the solid $\left(\overline{d_{3}}\right.$ and $\left.\overline{d_{4}}\right)$ - in the interface normal direction are used, schematically shown in the Fig. 1. $T_{1}$ and $T_{2}$ are the temperatures at the probes on the fluid side and $T_{3}$ and $T_{4}$ are the solid side probe temperatures. In either direction, probes are placed at a distance $\Delta x$ and $2 \Delta x$ from the interface, where $\Delta x$ is the uniform Eulerian grid spacing. The temperature at the probes are calculated by trilinear interpolation and using temperature at the probes, the surface temperature is calculated as:

$T_{i}=\frac{k_{f}\left(4 T_{1}-T_{2}\right)+k_{s}\left(4 T_{3}-T_{4}\right)}{3\left(k_{f}+k_{s}\right)}$

For very complex structure it may happen second fluid probe (second solid probe ) lies in the solid (fluid) or outside the CFD domain. For such cases only first-order scheme is feasible to calculate the solid surface temperature, detailed in Das et al. (2016b). 
Wall effects are important for slender packed beds and the cylindrical wall in the Cartesian computational domain is similarly resolved using an IBM. However, the velocity and temperature boundary condition at the inlet of the column requires special treatment, which is detailed here. At the inlet of the rectangular computational domain, a specified inlet velocity $\left(u_{\text {inlet }}\right)$ is assigned for all the cells that have their cell-center inside the column. For the rest of the cells (i.e. outside the column) a zero inlet velocity is specified. As a result, numerically, the total face area through which a constant inlet velocity is specified $\left(A_{S, \text { Num }}\right)$ is not necessarily equal to the cross-section of the column $\left(A_{S}=\frac{\pi}{4} D^{2}\right)$. To maintain the desired volumetric flow rate, the inlet plug velocity is corrected as,

$u_{\text {inlet }}^{\prime}=\frac{A_{S}}{A_{S, \text { Num }}} u_{\text {inlet }}$

When the flow is in the $x$ - direction, at a particular constant $x-$ plane,

$A_{S, N u m}=\sum_{j=1: n y} \sum_{k=1: n z}\left(f_{j k} \Delta y \Delta z\right)$

where $\Delta y$ and $\Delta z$ are the grid size in the $y-$ and $z$ - directions. $n_{y}$ and $n_{z}$ are equal and represent the number of grid cells in the $y-$ and $z$ - directions. $f_{j k}$ is either 0 or 1 based on the location of cell-center of an individual cell; it is 0 if the cell is outside the column and 1 if it is inside the column. To check the accuracy of the method we have simulated a case of single-phase laminar flow and heat transfer in a circular conduct. Simulations are performed at $R e_{D}=20$ and $P r=10$. A uniform constant velocity and temperature was prescribed at the inlet, at the outlet the pressure was prescribed along with zero gradient conditions for all other parameters, and no-slip and constant wall temperature conditions were used at the channel circular wall. The length of the channel was chosen as 20 times the diameter $(D)$, so that in the majority of the tube the system is fully developed both in terms of the radial temperature and velocity distribution. At fully developed condition, the simulation results are compared with the analytically obtained Darcy friction factor, $f_{D}=\frac{d p / d x}{\rho u_{i n e t}^{2} / 2 D}=\frac{64}{R e}=3.2$ and Nusselt number, $N u=3.6568$. The simulations are performed for four different grid resolutions, i.e. 10, 20, 40 and 60 grid cells across the diameter of the channel. The computed values of the fully developed $N u, f_{D}$ and the maximum relative deviation to the theoretical parabolic velocity profile, i.e. $\Delta u_{\max }=\frac{\left|u_{N u m}-u_{A n a}\right| \max }{u_{\text {max }}}$ are shown in Table 2. The computed correction factor $\left(A_{S} / A_{S, \text { Num }}{ }^{u_{\text {Ann }}}\right.$ for the inlet velocity amounted to 0.981748, $0.987232,0.994175$, and 0.999800 for the four different grids respectively. Table 2 shows an excellent agreement with analytical results.

\subsection{Random packings by discrete element method (DEM)}

There are two major techniques for generating a random packing structure: experimental tomography of the column and discrete element method (DEM) based numerical simulation. The Džiugys and Peters (2001) is generally used to simulate the flow dynamics of granular material. In this method, the motion of the particles are determined by applying Newton's second law of motion to each particle. For $p-t h$ particle the generalized form of the linear and angular motion equations are:

Table 2

Comparison of simulation and analytical results for flow through a circular duct.

\begin{tabular}{llll}
\hline Grids $\left(n_{x} \times n_{y} \times n_{z}\right)$ & $N u$ & $\% \Delta u_{\max }$ & $f_{D}$ \\
\hline $200 \times 10 \times 10$ & 3.6702 & 2.224 & 3.1927 \\
$400 \times 20 \times 20$ & 3.6623 & 0.538 & 3.1988 \\
$800 \times 40 \times 40$ & 3.6594 & 0.128 & 3.1998 \\
$1200 \times 60 \times 60$ & 3.6592 & 0.061 & 3.1999 \\
Analytical solution & 3.6568 & n.a. & 3.2 \\
\hline
\end{tabular}

$m_{p} \frac{d \bar{V}_{p}}{d t}=\bar{F}_{p} ; \quad \frac{d \bar{\chi}_{p}}{d t}=\bar{V}_{p}$

$I_{p} \frac{d \bar{\omega}_{p}}{d t}=\bar{T}_{p} ; \quad \frac{d \bar{\theta}_{p}}{d t}=\bar{\omega}_{p}$

where $m_{p}, I_{p}, \bar{\chi}_{p}$ and $\bar{\theta}_{p}$ stand for mass, moment of inertia, location of the center of mass and angular position of particle $p . \bar{V}_{p}$ and $\bar{\omega}_{p}$ are the particle linear and angular velocity; $\bar{F}_{p}$ and $\bar{T}_{p}$ represent the total force and torque acts on the $p-t h$ particle. The collision between two particles or particle to wall modeled by soft contact-force model (Strack and Cundall, 1978), where the total force is calculated based on the particle deformation/ overlap. When two particles strikes each other, at the contact point normal to the particle surface, they experience the elastic force $\left(\bar{F}_{e l}\right)$, proportional to the deformation of the particles and the viscoelastic damping forces $\left(\bar{F}_{d n}\right)$ proportional to the normal relative velocity between the particles. In the tangential direction of the contact, the tangential force $\left(\bar{F}_{t, p q}\right)$ comprises of Coulomb type friction force and a dynamic forces proportional to the tangential relative velocity and deformation between the particles. Hence, generalized form of the the collision force on $p$ th particle by $q$ th particle reads as:

$$
\begin{aligned}
\bar{F}_{p q}= & \bar{F}_{e l, p q}+\bar{F}_{d n, p q}+\bar{F}_{t, p q}=k_{n} \delta_{n, p q} \bar{n}_{p q}-\gamma_{n} \bar{v}_{r n}-\min \left\{\mu_{c}\left|\bar{F}_{e l, p q}\right|,\right. \\
& \left.\left|-k_{t} \delta_{t, p q}-\gamma_{t} \bar{v}_{r t}\right|\right\} \bar{t}_{p q}
\end{aligned}
$$

where $\bar{n}_{p q}$ and $\bar{t}_{p q}$ represent the unit normal and unit tangential vector at the contact point, respectively. $\delta_{n, p q}$ is normal overlap between particle $p$ and $q$, whereas $\delta_{t, p q}$ is the tangential displacement vector between the particles. $\bar{v}_{r n}$ and $\bar{v}_{r t}$ are the normal and tangential relative velocity between the particles. $k_{n}$ and $k_{t}$ are elastic constant for normal and tangential direction; whereas $\gamma_{n}$ and $\gamma_{t}$ are viscoelastic damping constant for normal and tangential contact respectively. $\mu_{c}$ represents Coulomb type dynamic friction coefficient. Hertz-Mindlin non-linear contact force model, available in the open-source DEM code LIGGGHTS (www.liggghts.com) has been used to calculate the material constants.

The present allows to have multiple collision/ contact between the particles at the same time, which is essential for static packings. Total force acts on the $p^{\text {th }}$ particle will be summation of all the forces by other particles (total number of particle $n$ ), wall and gravity $(\bar{g})$ :

$\overline{F_{p}}=m_{p} \bar{g}+\sum_{q=0, q \neq p}^{n-1} \bar{F}_{p q}$

Similarly, total generated torque on $p^{\text {th }}$ particle,

$\bar{T}_{p}=\sum_{q=0, q \neq p}^{n-1} \bar{d}_{c, p q} \times \bar{F}_{p q}$

where $\bar{d}_{c, p q}$ is radius vector pointing from the center of mass of particle $p$ to contact point with particle $q$ or the cylindrical wall. For spherical particles, a rolling torque resistance also added to the total torque calculation. The time integration of Eq. (10) and (11) are performed by leap-frog scheme, which provides stable solution.

The dynamics of the particles and as a result, the resulting packing depends on the mechanical properties of the solid spheres and the wall. For DEM simulations, the mechanical properties of the particles are set according to those of glass spheres with a surface roughness (friction factor) that is chosen to be typical for catalytic particles. A total of seven column diameter $(D)$ to particle diameter $(d)$ with $N=D / d=4,5,6,7,8,12,16$ are used. A maximum particle overlap of $1 \%$ of the particle diameter is obtained from the DEM-code. The DEM simulation parameters are listed in Table 3.

In Fig. 2 the transient filling procedure is shown. Initially, clusters of particles are randomly placed near the top of the column. The particles are placed randomly by a Monte Carlo simulation procedure available in LIGGGHTS and allowed to fall due to gravity. New groups of particles are used to fill the column up-to a desired height of 
Table 3

Parameters used in DEM simulations to generate random packings of spherical particles.

\begin{tabular}{lll}
\hline & value & units \\
\hline Particle diameter $(d)$ & 0.03 & $\mathrm{~m}$ \\
Cylinder diameter $(D)$ & $0.12,0.15,0.18,0.21,0.24,0.36,0.48$ & $\mathrm{~m}$ \\
Number of particles & $220,340,510,680,940,2100,3700$ & - \\
Particle density & 2300 & $\mathrm{~kg} / \mathrm{m}^{3}$ \\
Young modulus & $4.92 \times 10^{10}$ & $\mathrm{~Pa}$ \\
Poisson's ratio & 0.23 & - \\
Coefficient of restitution & 0.94 & - \\
Coefficient of static friction & 0.2 & - \\
Coefficient of rolling friction & 0.02 & - \\
DEM time-step & $10^{-7}$ & $\mathrm{~s}$ \\
\hline
\end{tabular}

approximately $H=15 d$. After inserting the final group of the particles, the DEM simulation is continued until all particles have come to rest. In Fig. 3 the final random packing for different $N$ are shown. The locations of the spheres are stored so they can be imported into the IBM based DNS code.

In general, the bed porosity depends on (i) particle to column diameter ratio, (ii) particle size and shape, (iii) surface roughness of the particles, (iv) loading of the method, and $v$ ) the external agitation of the column or fluidization. There is no generalized correlation which relates the bed porosity with all these parameters (de Klerk, 2003). At the same time, random placement of the particles during the filling process may change the bed porosity. In our DEM simulation, we have used spherical particles of a specific roughness (coefficient of friction) without any external agitation of the column. In this case, the packing generation is random due to the arbitrary placement of groups of particles and the number of particles per group. We have first studied the effect of initial random placement of particles on the resulting packing porosity by running the same simulation several times while keeping all other setting the same. We found negligible $(\sim 1 \%)$ differences on the overall porosity. Then we performed three different simulations only varying the number of particles per group such that the porosity of the filling cylinder turns into approximately $0.7,0.8$ and
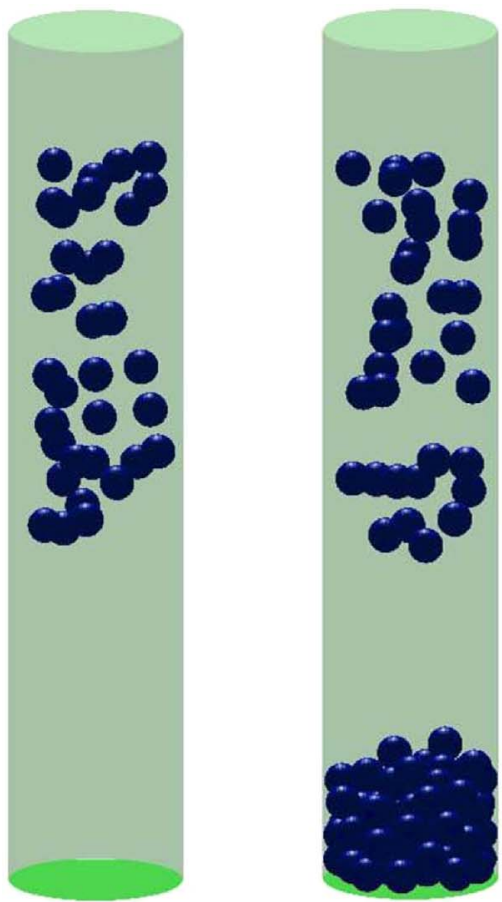

0.9 , and here too, we found negligible differences on the overall porosity. However, if we place the particles very closely (porosity of filling cylinder $\sim 0.4$ ) in the initial group, then the number of particles per group turns out crucial and changes the overall porosity of the bed. For the present pouring method used in this work, we can conclude that the packing structure is more or less unique.

\subsection{Calculation of radial and axial porosity distribution}

For a very large column, the global porosity is generally calculated on basis of the number of particles and packing height. However to calculate the radial and axial porosity profile either 3D imaging techniques (Zhang et al., 2006) or numerical techniques (Mueller, 2012) as used in this work are required. To this end, based on the particle locations, we first calculate the porosity at each and individual Cartesian cell of the CFD domain. From the 3D porosity distribution of the cylindrical bed, we calculate the porosity distribution (i) along the axis of the column averaged over each cross-section, and (ii) along the radius averaged over both axial and azimuthal direction. In the axial direction, at the bottom section of the bed particles are oriented in an ordered manner (bottom wall effect) and also in the current filling process, at the top section of the column the particles are packed loosely. After generating the packings by DEM simulations, we remove the particles from both the bottom section and the top section of the packing (up to 2-3 particle diameters) and export the packing to our CFD solver. As a result, the reported bulk porosity of the bed, radial porosity profiles and the flow simulation results are independent of the bed height.

To calculate the porosity at each computational cell, at first all the computational cells that are fully inside a solid particle are assigned a value $\varepsilon=0$ and those fully outside the solid particles a value $\varepsilon=1$. We call a computational cell fully inside the solid when all the eight vertices are inside the solid body. To calculate the porosity for cells that are partially occupied by particles, we need to calculate the volume of a very complex 3-D geometrical shapes created by the intersection of the grid lines and the particle surface. In the present study, this is approximated numerically, by first dividing all the relevant cells into
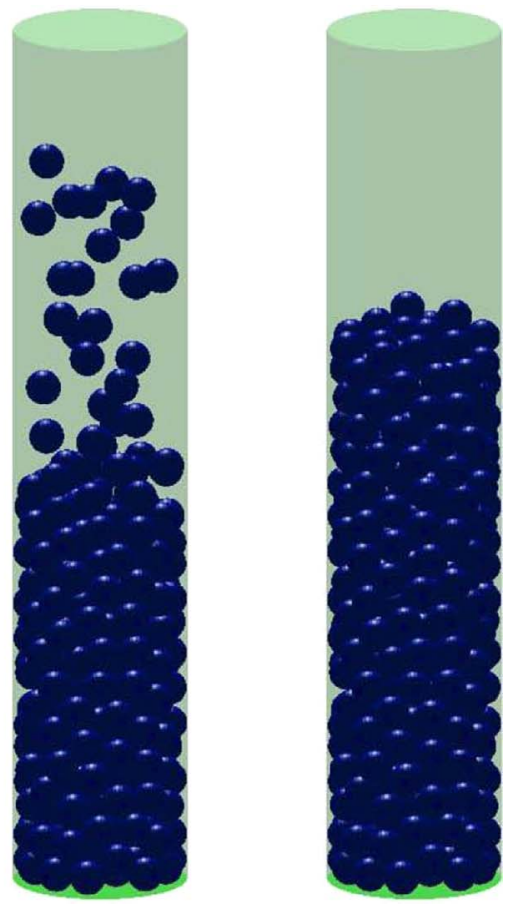

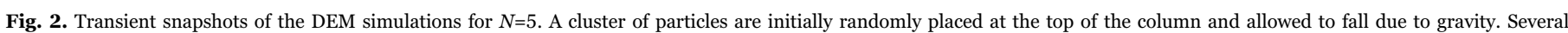
clusters are used to fill the column to an approximate height $H=15 d$. 


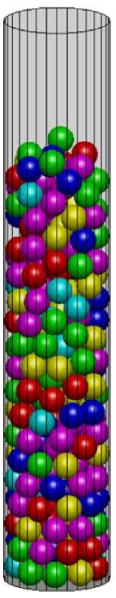

$\mathbf{N}=\mathbf{4}$

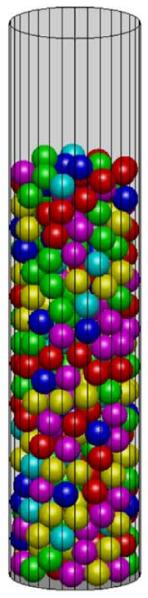

$\boldsymbol{N}=\mathbf{5}$

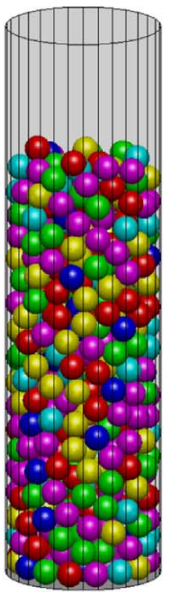

$\mathbf{N}=\mathbf{6}$

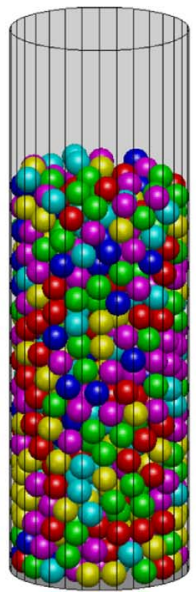

$\mathbf{N}=\mathbf{7}$

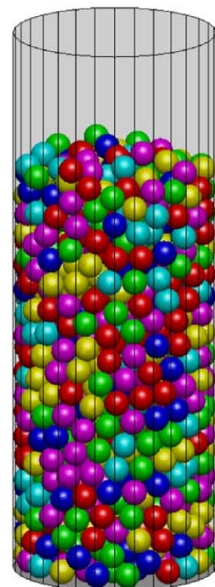

$N=8$

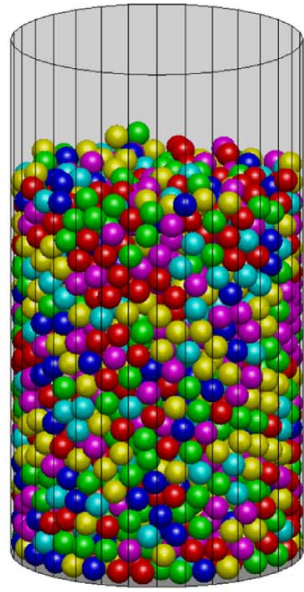

$N=12$

Fig. 3. Random packing of spherical particles obtained from DEM simulations for $N=4,5,6,7,8,12$, respectively. Different particle colours are used for proper visualisation.

very small sub-cells and then counting the number of sub-cells that are in and outside the particles. The porosity can now easily be obtained by dividing the number of fluid sub-cells by the total number of sub-cells. Fig. 4-a schematically represents the methodology in 2-D. In this figure, only the computational cells that contain solid interface are divided into $4 \times 4$ sub-cells; the blue line indicates the surface of a spherical particle, white sub-cells are outside, and the dark sub-cells are inside the particle. For instance: for the central cell, the obtained porosity is approximated as $\varepsilon=3 / 16=0.1875$. The accuracy of this method will improve as the number of sub-cells is increased. In all calculations presented in this work we have divided each cell into $10 \times 10 \times 10$ sub-cells which provide us with an accuracy of $O(0.1) \%$. A similar approach has been used to calculate the porosity near the column wall, where cells are also cut by the cylindrical wall and decrease in cell volume (fluid) is also considered to calculate porosity. To decrease the computational expenses, at first, we loop over all the particles, create a bounding box around each particle, and only examine the computational cells inside the bounding box to assign

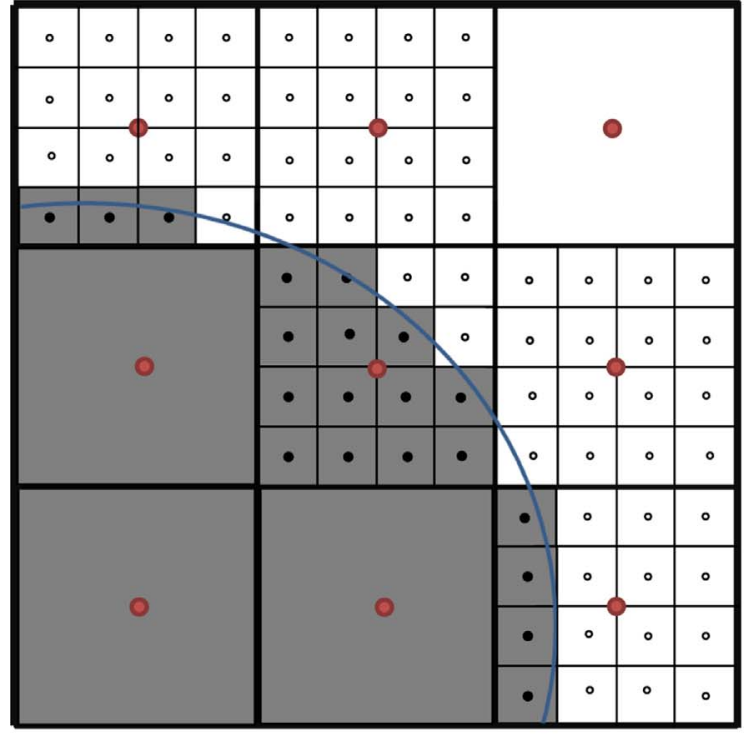

- Cell-center of the main computational grid

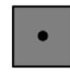

Sub-grid inside the solid particle

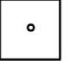

Sub-grid outside the solid particle

Surface of the solid particle

(a)

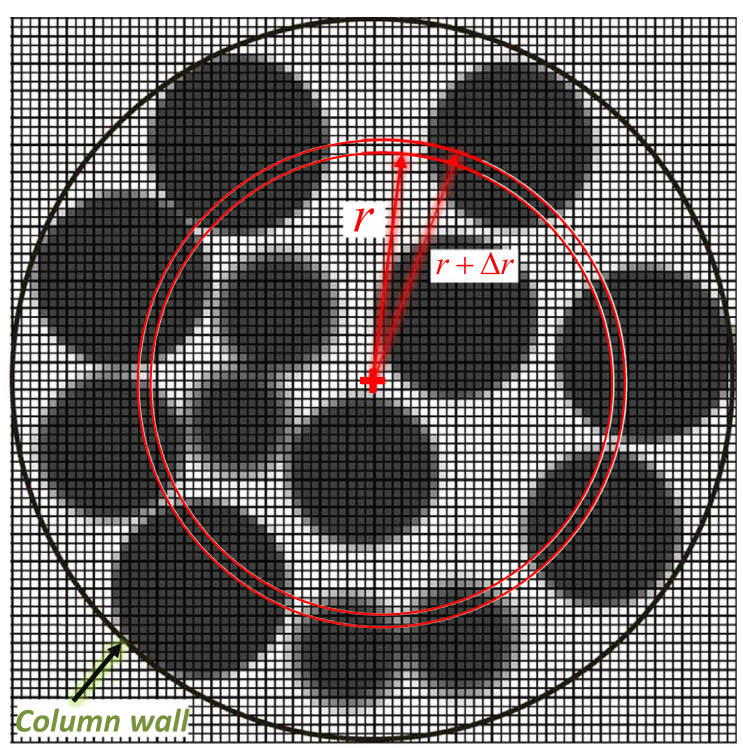

$\varepsilon$

0.00

0.25

0.5

0.75

1.00

(b)

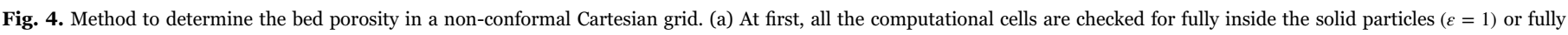

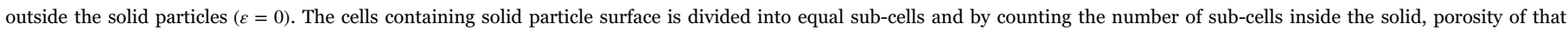

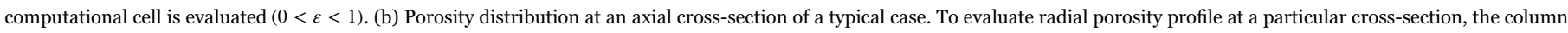

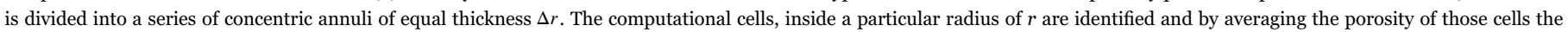
radial porosity is evaluated. After evaluation radial porosity profile at each cross-section, it is averaged along the axial direction. 
porosity value. In Fig. 4-b, the local porosity distribution at a column section is shown for a typical case. The axial porosity profile $\left(\varepsilon_{a}\right)$ is obtained easily by averaging porosity at each cross-section. In the Cartesian domain, to calculate the radial porosity profile $\left(\varepsilon_{r}\right)$, each cross-section of the bed is divided into a serious of annuli of thickness $\Delta r$. In Fig. 4-b one such annulus at radius $r$ is shown. The computational cells inside the particular annulus are identified and by simple averaging the radial porosity at radius $r$ is calculated. For this random packing, after evaluation radial porosity profile at each cross-section, it is averaged along the axial direction. Please note we have chosen $\Delta r$ equal to the Cartesian grid spacing and the method proposed here can easily be used for non-spheral particles.

\section{Results and discussions}

\subsection{Simulation cases and settings}

Fully resolved flow and heat transfer simulations are performed for in total seven different flow domains $(N=4,5,6,7,8$ and the core section of $N=12$ and 16 column) with five different particle Reynolds numbers $\left(R e_{d}=1,20,50,100,250,500\right)$. For the column with $N=4$ to 8 , the wall effect is important and no-slip boundary conditions at the cylindrical wall are implied (Fig. 5-a). However, for the case of $N=12$ and $N=16$, wall effects are small, and hence only the core section of the packing is considered giving a rectangular computation domain of cross-section $6 d \times 6 d$ (see Fig. 5-b). As such, the latter two cases represent $N \rightarrow \infty$. Free-slip boundary conditions are applied to the side walls in those cases. In this paper the seven different cases are referred to as $N 4, N 5, N 6, N 7, N 8, N i n f 1$, and $N \inf 2$ respectively for further discussion. For all the cases, we have removed $\sim 3$ particle layers of the bottom part of the bed and $\sim 2$ particle layers from the top of the very loosely packed bed. This provides us with a packing height of approximately 10 times the particle diameter along the axial direction, where the cross-sectional average porosity remains more or less homogeneous. To minimize the influence of the boundary conditions at the inlet and outlet, an inlet section of length equal to $3 d$ and an outlet section of approximately $6 d$ are added respectively upstream and downstream of the spherical packing. In Fig. 5-a, the column, packing, inlet, outlet sections for $N 5$ ) and in Fig. 5-b core section of $N=16$ column, i.e. Ninf 1 are shown. Fig. 5-c shows a very small section of the $N=16$ column to check the grid independence (Appendix A). For Fig. 5$\mathrm{b}$ and c, no-slip boundary condition are specified to the side-walls.

At the inlet of the bed a fixed superficial velocity $\left(U_{s}=1 \mathrm{~m} / \mathrm{s}\right)$ is specified and the outlet of the column is subject to a prescribed pressure condition. For all the simulations a constant particle diameter, $d=0.03 \mathrm{~m}$ has been used. We have also tested the effect of the inlet and outlet section length by extending the domain up to $10 d$ and $15 d$, respectively and only a negligible difference was observed. For the heat transfer analysis, a constant fluid temperature $\left(T_{\text {inlet }}=300 \mathrm{~K}\right)$ at the inlet is specified. The column wall of the inlet section is set equal to $T_{\text {inlet }}$, whereas the main part of the column (including the packing and the outlet section) are kept at a constant temperature $T_{\text {column }}=400 \mathrm{~K}$. In this way, we can ensure that no heat transfer occurs between the entering fluid and the wall of the inlet section. The temperature is solved both inside and outside the solid particles (conjugate heat transfer model). At the solid-fluid interface continuity of heat flux and temperature are ensured by our IBM model. For the fluid, $P r=1$ and a solid-fluid conductivity ratio, $k_{s} / k_{f}=10$ is used for almost all the simulations. This ratio is typically found for glass/air systems. As we are only interested in the steady state, the fluid and solid specific heat and density are considered to be the same. Besides this, two different solid to fluid conductivities of 1 and 100 and two different Prandtl number of 0.5 and 2 are considered for the $N 6$ column to check the effect of the conductivity ratio and Prandtl number on the overall heat

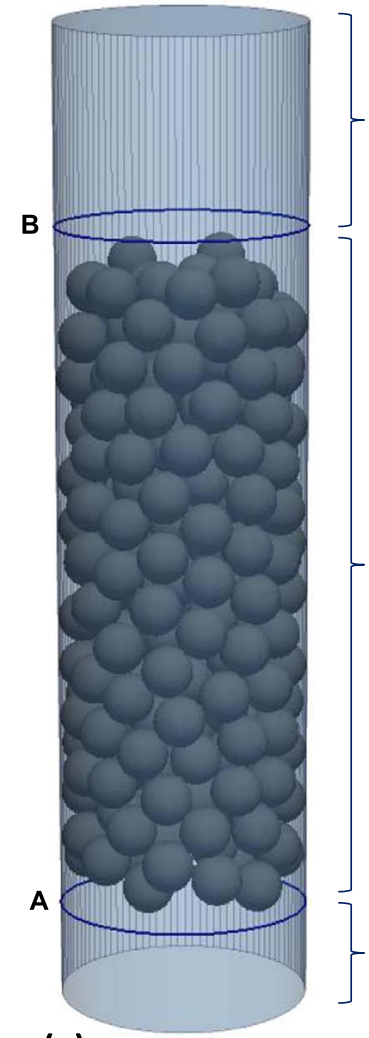

(a)

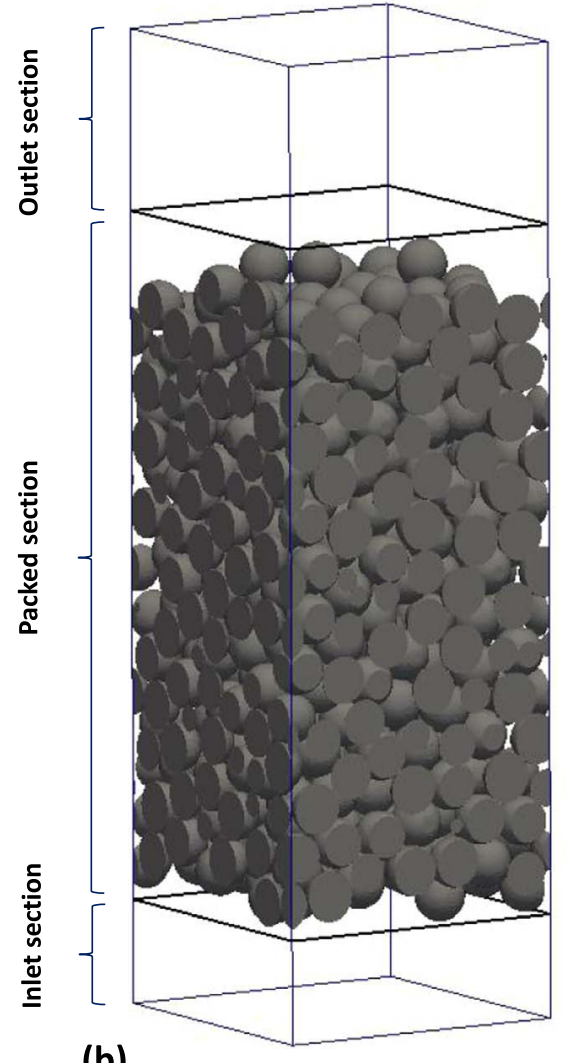

(b)

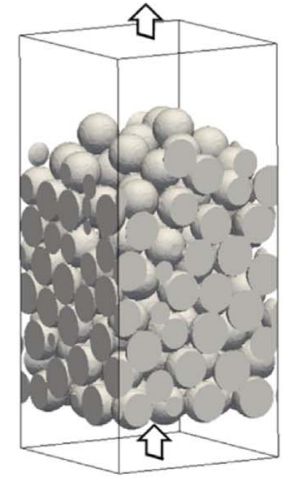

(c)

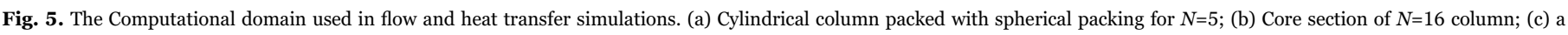

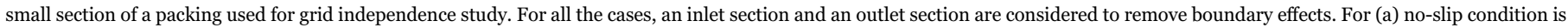
specified at the cylindrical wall, whereas for (b) and (c) all the side walls are specified as free-slip walls. 
Table 4

Parameters used in CFD simulations; For the two cases indicated with *only the core section of the $N=12$ and 16 column is considered (i.e. Ninf 1 and Ninf 2 ). The porosity value reported here is the porosity of the core section, not the porosity of the full column.

\begin{tabular}{lll}
\hline Parameter & Values & units \\
\hline$\Delta x=\Delta y=\Delta z$ & $7.5 \times 10^{-4}$ & $\mathrm{~m}$ \\
Time step $(\Delta t)$ & $\sim 10^{-5}$ & $\mathrm{sec}$ \\
Particle diameter $(d)$ & 0.03 & $\mathrm{~m}$ \\
Column diameter $(D)$ & $0.12,0.15,0.18,0.21,0.24,0.36,0.48$ & $\mathrm{~m}$ \\
Column height & 0.585 & $\mathrm{~m}$ \\
Average bed porosity $(\varepsilon)$ & $0.455,0.446,0.428,0.419,0.4,0.37^{*}$, & - \\
& $0.369^{*}$ & \\
Superficial velocity $\left(U_{s}\right)$ & 1 & $\mathrm{~m} / \mathrm{s}$ \\
Fluid viscosity $\left(\mu_{f}\right)$ & 0.03 & $\mathrm{~Pa}-\mathrm{s}$ \\
Fluid/solid density & $1,20,50,100,250,500$ & $\mathrm{~kg} / \mathrm{m}^{3}$ \\
$\quad\left(\rho_{f}=\rho_{s}\right)$ & $1,20,50,100,250,500$ & - \\
$\quad \begin{array}{l}\text { Particle Reynolds } \\
\text { number }\left(R e_{d}\right)\end{array}$ & 0.03 & $\mathrm{~W} /(\mathrm{m} \mathrm{K})$ \\
$\quad \begin{array}{l}\text { Fluid thermal } \\
\text { conductivity }\left(k_{f}\right)\end{array}$ & 1 & $\mathrm{~J} / \mathrm{K}$ \\
$\quad \begin{array}{l}\text { Fluid/ solid heat } \\
\text { capacity }\left(C_{P, f}=C_{P, s}\right)\end{array}$ & $0.03,0.3,3 \& 30$ & $\mathrm{~W} /(\mathrm{m} \mathrm{K})$ \\
$\quad \begin{array}{l}\text { Solid thermal } \\
\text { conductivity }\left(k_{s}\right)\end{array}$ & & \\
\hline
\end{tabular}

transfer rates. Cartesian grids of equal spacing $(\Delta x=\Delta y=\Delta z)$ are used and a grid dependence study suggested that 40 grid cells across the diameter of each particle provide grid independent results. The timestep is chosen such that the maximum Courant-Friedrichs-Lewy (CFL) number remains below 0.4 for all the cases. Detailed numerical settings are presented in Table 4.

\subsection{Bed porosity}

The radial porosity profile $\left(\varepsilon_{r}\right)$ is an important parameter in the context of flow channeling near the wall and homogeneity of the packed bed. To characterize the radial variation of porosity in cylindrical beds, de Klerk (2003) proposed the following relation that is averaged in the axial and azimuthal directions:

$\varepsilon(p)= \begin{cases}2.14 p^{2}-2.53 p+1, & p \leq 0.637 \\ \varepsilon_{b}+0.29 e^{-0.6 p}[\cos (2.3 \pi(p-0.16))]+0.15 e^{-0.9 p}, & p>0.637\end{cases}$

where $p=\frac{R-r}{d}$ is the normalized wall distance and $R=D / 2$, radius of the column. In this equation $\varepsilon_{b}$ represent the bulk porosity for an infinitely large column diameter, i.e. in the absence of the wall effects. According to de Klerk (2003), effects of the mode of packing and the surface roughness of the spheres on the overall porosity distribution are embodied in $\varepsilon_{b}$, which in our case equals $\varepsilon_{b}=0.37$ (obtained from the core-section of the $N=12$ and $N=16$ column). In Fig. 6 the radial porosity is plotted as a function of the normalized wall distance $(p)$ along with the correlation proposed by de Klerk (2003). It shows that, both the amplitude and the frequency of the porosity distribution near the wall matches very well with the correlation. For a very slender column, the maximum deviation is mainly found near the axis of the column. This behavior was also observed by Eppinger et al. (2011).

The particles near the wall have an ordered packing due to the presence of the wall regardless of the particle to column diameter. The shape of the radial porosity distributions in Fig. 6 is due to the alignment of the outer ring of the particles against the column wall. Fig. 7 shows the distribution of the particle centres projected on the cross-section of the cylinder. Near the wall, a distinct/ sharp ring like structure forms. The ring-like structures propagate few particles inward, but it becomes more and more defused. It is the reason for the oscillatory trend of radial porosity profile (Fig. 6) with peaks at an integer number of particle diameters. The oscillation dampens out quickly as the distance from the wall increases.

Fig. 8 shows the axial porosity distribution (averaged over each cross-section) with normalized axial distance $(m=x / d)$. A similar oscillation is found due to the presence of the bottom wall. Please note that for a very tall column, this effect can safely be neglected. However, if the column size is relatively shallow, during averaging, this effect may lead to inconsistent results. To avoid this, in CFD domain only middle section $(3 \leq m \leq 15)$ of the generated packings from DEM simulations are exported. It results more or less homogeneous axial bed porosity through out the bed.

Fig. 9 shows the variation of bulk or overall porosity with different particle to column diameter ratios. The DEM results are compared with the correlation by Jeschar (1964), de Klerk (2003) and Dixon (1988), which respectively read:

$\varepsilon=0.375+\frac{0.34}{N}$

$\varepsilon=\varepsilon_{b}+0.35 e^{-0.39 N}, \quad \varepsilon_{b}=0.375$ to 0.391

$\varepsilon=0.4+\frac{0.05}{N}+\frac{0.412}{N^{2}}$

It is found that the correlation proposed by Jeschar (1964) matches well with the present DEM results. In Fig. 9 the upper limit and the lower limit of the porosity variation with $N$ are shown for De Klerk's correlation (de Klerk, 2003). By reviewing several experimental data, De Klerk proposed $\varepsilon_{b} \sim 0.375-0.391$ for random pouring of spherical particles in a cylindrical container without any mechanical vibration. Our present DEM simulation results are very close to the upper limit of the porosity estimated by De Klerk's correlation.

\subsection{Hydrodynamics}

\subsubsection{Pressure drop}

As mentioned earlier, in total seven different packing configurations ( $N 4$ to Ninf 2) have been considered and the particle Reynolds number has been varied from 1 to 500. For very low Reynolds numbers (Darcy regime or creeping flow regime), the pressure drop is only balanced by the shear stress at the cylindrical wall and the particle surfaces. When the Reynolds number is increased (Forchheimer regime), the flow inertia starts playing a role and the total pressure drop contains viscous and inertial contributions. Sometimes, in porous medium literature these two flow regimes are referred to as laminar and turbulent regimes, which is misleading (Niven, 2002). Please note that, in the present study the flow is still laminar at $R e_{d}=500$ and the pressure drop offered by a porous medium to the motion of the fluid at finite Reynolds number is expressed as the sum of the viscous and kinetic energy losses:

$\frac{\Delta p}{\Delta x}=a \mu U_{s}+b \rho U_{s}^{2}$

The values of $a$ and $b$ depend on the type and the structure of the porous medium. A lot of effort has been made by several researchers to form generalized functions for $a$ and $b$ in terms of porosity and the length scale of the porous medium. For creeping flows, Carman first proposed $a$ in the form of a hydraulic radius and tortuosity. For porous media made of mono-disperse spheres Ergun proposed:

$a=A \frac{(1-\varepsilon)^{2}}{\varepsilon^{3}} \frac{1}{d} \quad$ and $\quad b=B \frac{(1-\varepsilon)}{\varepsilon^{3}} \cdot \frac{1}{d^{2}}$

where $A=150$ and $B=1.75$ are known as the Ergun constants. This formulation is also extended for close packings of non-spherical particles with the help of sphericity. Ergun proposed this correlation for particles filled in a very large container where wall effects can be neglected. However, in the case of slender columns the pressure drop is altered by two effects: (i) the near wall porosity fluctuation in the annular near wall region up to about two particle diameters from the 

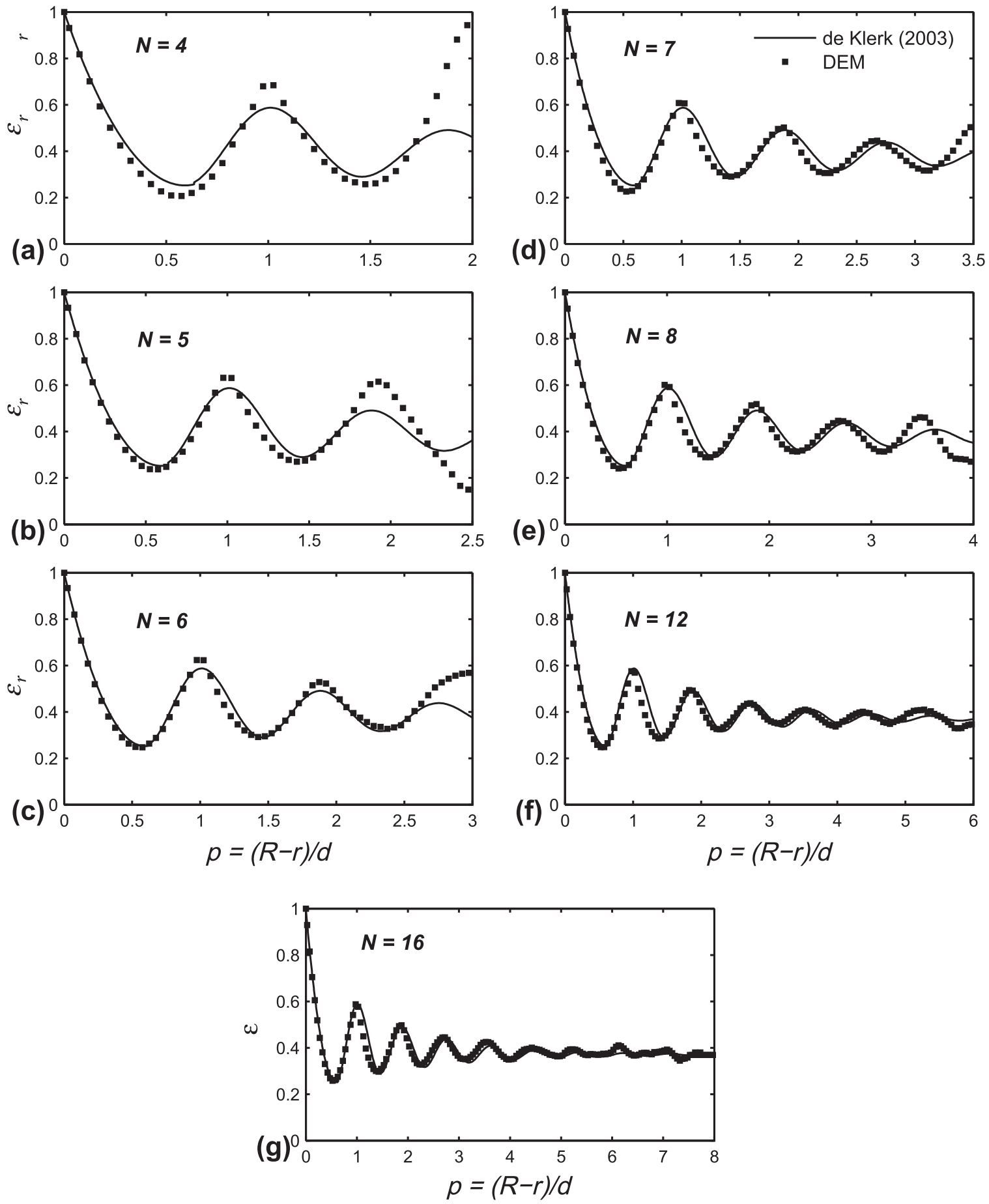

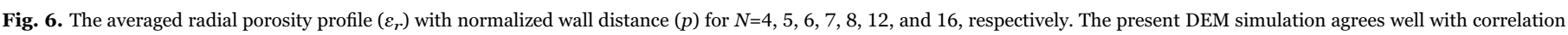
proposed by de Klerk (2003).

wall, and (ii) the wall friction offered by the cylinder wall. As seen in the Fig. 9, $N$ also changes the porosity of the bed, however for infinitely wide columns it converges to a fixed value.

In the review paper by Macdonald et al. (1979), they compared the experimental results of other authors with the Ergun correlation and proposed different values of the constants. In their studies, $A=180$ for the viscous component of the pressure drop had been adopted from the Carman equation and $B=1.8$ was found by fitting a large amount of experimental data including the original results by Ergun. They showed that the modified Ergun correlation can describe the pressure drop with an accuracy of $\pm 25 \%$. Most probably, to fit the data at higher Reynolds number, Ergun reduced the value of $A$ (Nemec and Levec,
2005). The porosity function, i.e. $(1-\varepsilon)^{2} / \varepsilon^{3}$ for the viscous term and $(1-\varepsilon) / \varepsilon^{3}$ for inertial term first proposed by Ergun was found to be very accurate by several authors (Nemec and Levec, 2005) for the case of very close packing $(0.35<\varepsilon<0.55)$. It indicates that, for a column with large diameter, if different packing configuration creates different porosities, the value of constants $A$ and $B$ should not change. For a close packing, by analytical formulation, Niven (2002) justified use of such porosity function for pressure drop calculations, however for dilute systems this function needs to be modified. Hence, most researchers have only tried to find the values of $A$ and $B$ for dense packings. There exists a large number of uncertainties in experimental results and as a result, a huge variation can be observed in the existing 

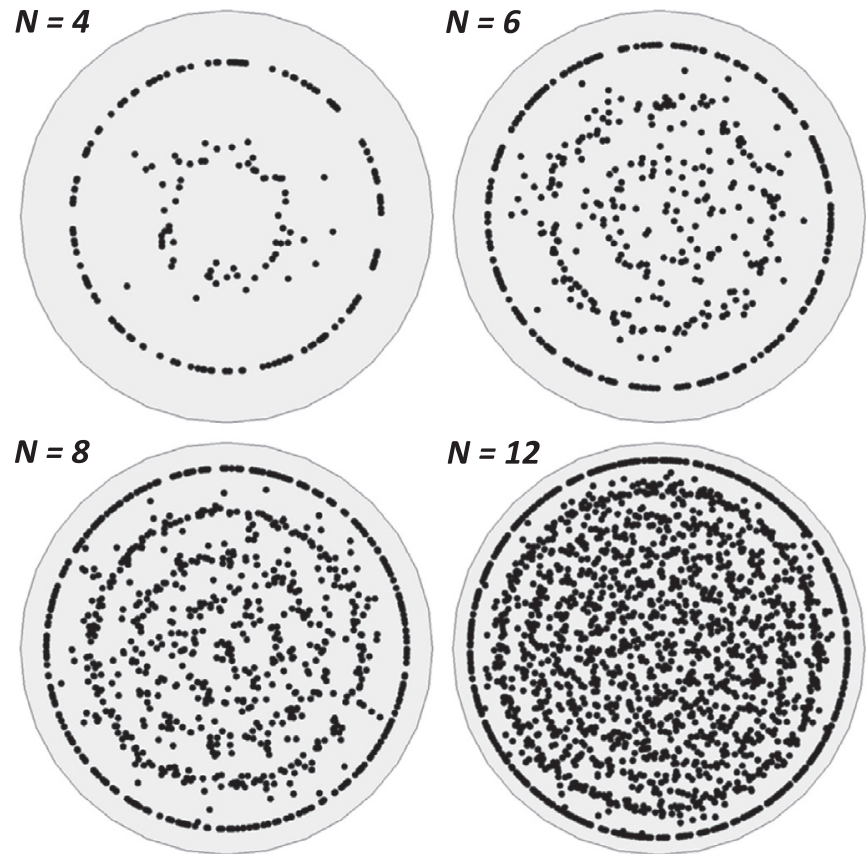

Fig. 7. The distribution of the particle centres projected on the cylinder cross-section.
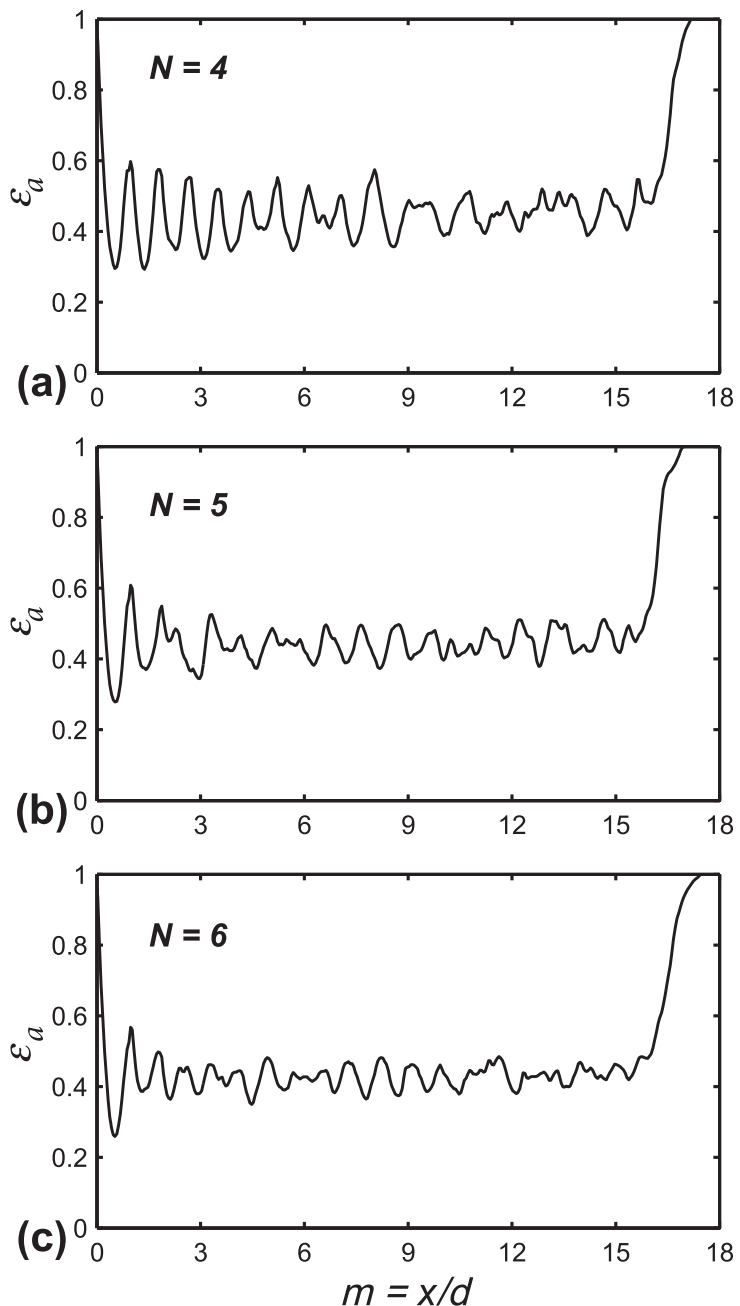

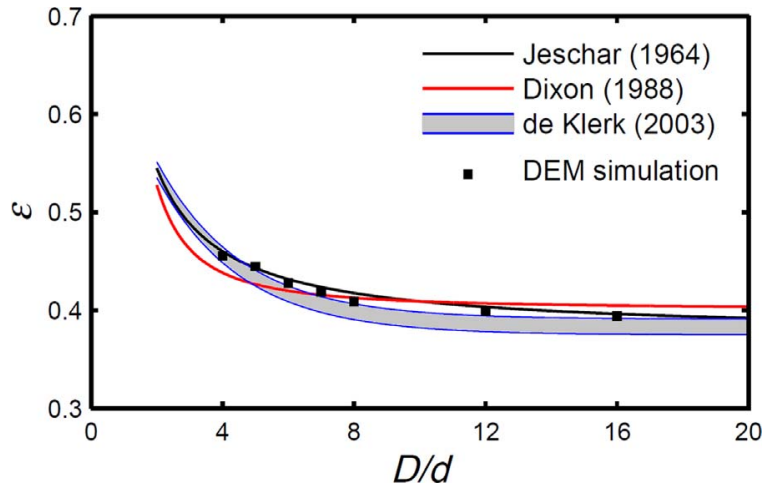

Fig. 9. The overall or bulk bed porosity with column-to-particle diameter ratio.

literature data. By means of fully resolved numerical simulation, we will try to find the values of $A$ and $B$ for different column-to-particle diameter ratio.

We first normalize the pressure gradient as follows:

$f=\frac{\Delta p / \Delta x}{\mu U_{s} / d^{2}}=A \frac{(1-\varepsilon)^{2}}{\varepsilon^{3}}+B \frac{(1-\varepsilon)}{\varepsilon^{3}} R e_{d}$

As a result the pressure drop becomes a linear function of $R e_{d}$ and

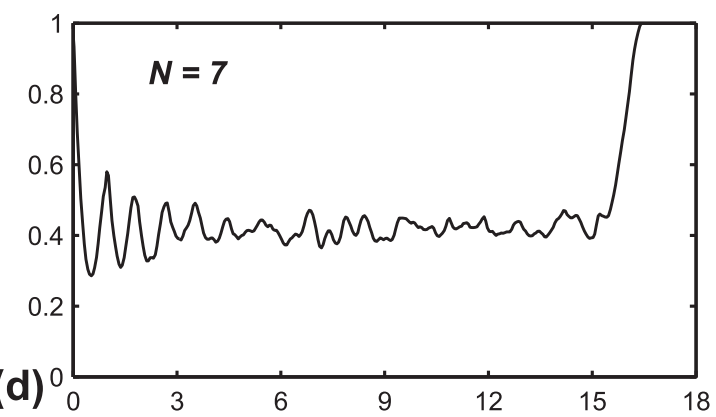

(e)
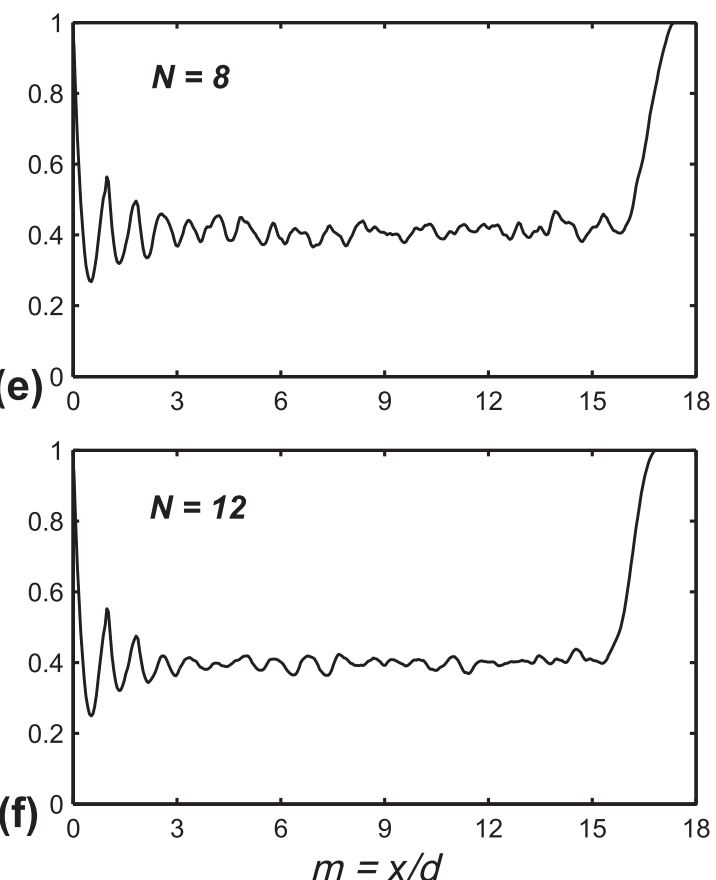

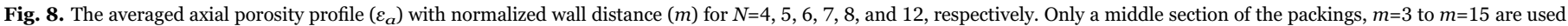
in CFD simulations and to calculate average bed porosity. 


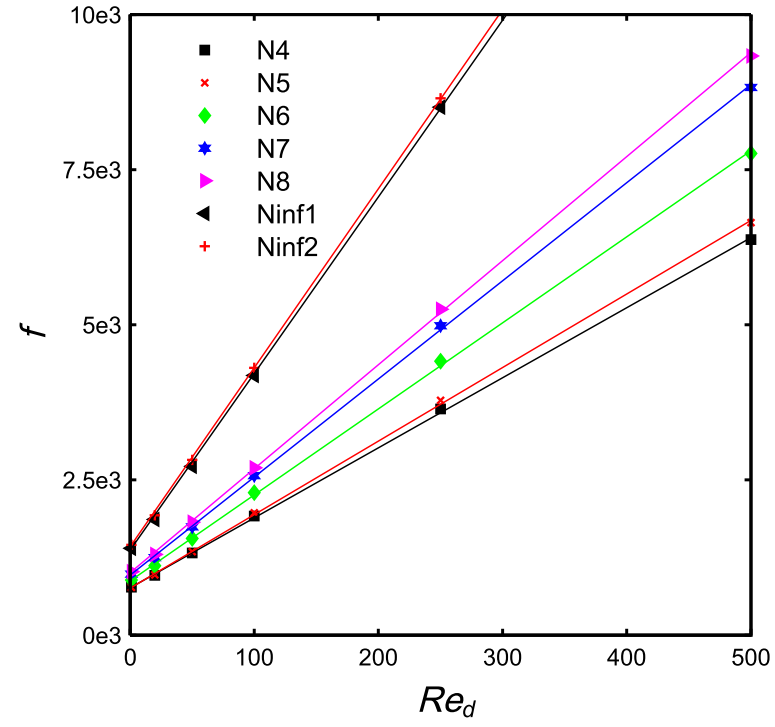

Fig. 10. Non-dimensional pressure drop $(f)$ with particle Reynolds number $\left(R e_{d}\right)$ for different column-to-particle diameter ratio $(N)$. Firm lines are the liner-fits for individual columns.

by linear fit we can easily find the values of of $A$ and $B$. In Fig. 10 the non-dimensional pressure drop $(f)$ versus particle Reynolds number $\left(R e_{d}\right)$ for different column-to-particle diameter ratios $(N)$ is plotted. It is found that with increasing $N$ the pressure drop increases, mainly due to the decrease in overall porosity of the bed. The pressure drop is a very strong function of bed porosity and any small change in bed porosity leads to a large change in pressure drop. It is interesting to compare the current simulation results with experiments and evaluate the values of $A$ and $B$ from the present fully resolved simulation. To account for the wall effect, the most popular pressure drop correlation is the correlation of Eisfeld and Schnitzlein (2001). In their correlation $A$ and $B$ are not constants, but vary with $N$ and $\varepsilon$ :

$$
\begin{gathered}
A_{E S}=154 A_{w, E S}, B_{E S}=\frac{A_{w, E S}}{B_{w, E S}}, A_{w, E S}=1+\frac{2}{3 N(1-\varepsilon)}, \\
B_{w, E S}=\left[\frac{1.15}{N^{2}}+0.87\right]^{2}
\end{gathered}
$$

They have reviewed pressure drop data of other researchers (2300

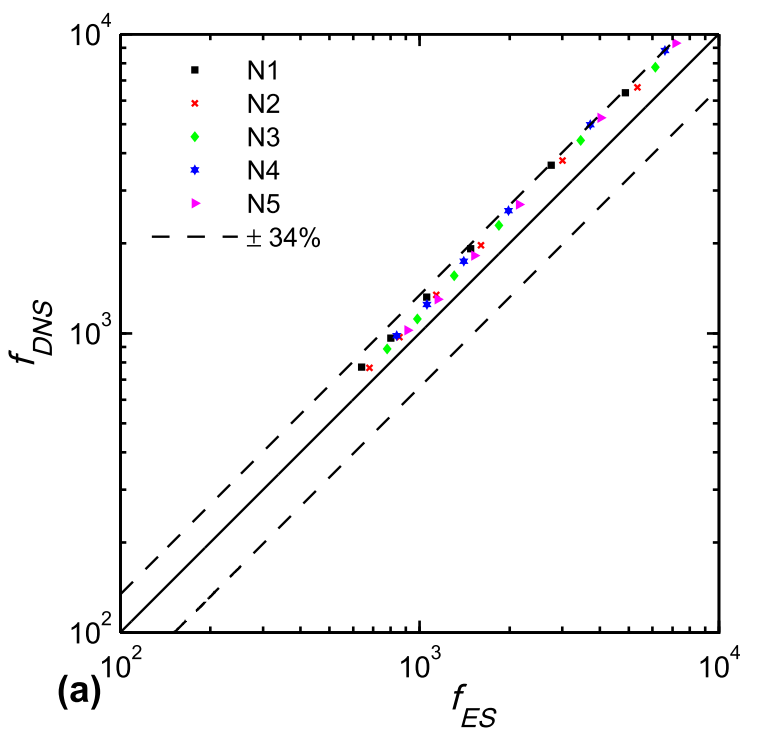

data points and 24 different correlations) and proposed the above correlation. This correlation fits most of the experimental data $(95 \%$ confidence level) for $N=2$ to $N \rightarrow \infty$ with an accuracy of $\pm 34 \%$. From Eq. (22) we can find that the pressure drop constants reach a value of $A_{E S}=154$ and $B_{E S}=1.32$ when $N \rightarrow \infty$, which is much lower than the values from the Ergun or modified Ergun correlation. In Fig. 11-a the non-dimensional pressure drop obtained from our simulations is compared with the Eisfeld and Schnitzlein correlation in a log-log plot for $N 4$ to $N 8$ columns. It is found that all the simulation results lie inside the reported error band. Fig. 11-b shows the variation of the modified friction factor $(\psi)$ with the modified Reynolds number $\left(R e_{d}^{\prime}\right)$, as defined by Ergun:

$\psi=\frac{\Delta p / \Delta x}{\rho U_{s}^{2} / d} \frac{\varepsilon^{3}}{(1-\varepsilon)}$

$R e^{\prime}{ }_{d}=\frac{1}{1-\varepsilon} R e_{d}$

Please note that in Fig. 11-b modified Ergun constants (Macdonald et al., 1979) are used and simulation results for $\operatorname{Ninf} 1$ and $\operatorname{Ninf} 2$ are compared. All the simulation results are within $\pm 25 \%$. In Appendix A we have shown the effect of the grid resolution on the friction factor for $R e_{d}=50$ and 500 considering a small section of a packing (Fig. 5-c). It shows that a grid resolution of $d_{p} / \Delta x=80$ (G80) provides grid independent results for finite Reynolds number flow. However, to reduce the computational expenses we have used $G 40$, which leads to an over-prediction of the pressure drop by $\sim 10 \%$. In Fig. 11-b, error bars for $R e_{d}=50$ and 500 are also shown. It can be observed that the deviation between the DNS results and the modified Ergun correlation decreases with the use of finer grids.

The low column-to-particle diameter ratio influences pressure drop in two ways, (i) the wall shear stress induces a pressure drop and, (ii) the increase in porosity near the wall reduces the pressure drop (see Fig. 9). So as compared to infinitely large columns, the overall pressure drop in a slender column is a trade off between these two effects, which depends on the Reynolds number. From the simulations we found that, $A$ decreases with increase in $N$ and $B$ first decreases and then increases. From the current numerical results we have obtained the following correlation for $A$ and $B$ :

$A_{w, D N S}=1+\frac{1.052}{\{N(1-\varepsilon)\}^{1.413}}$

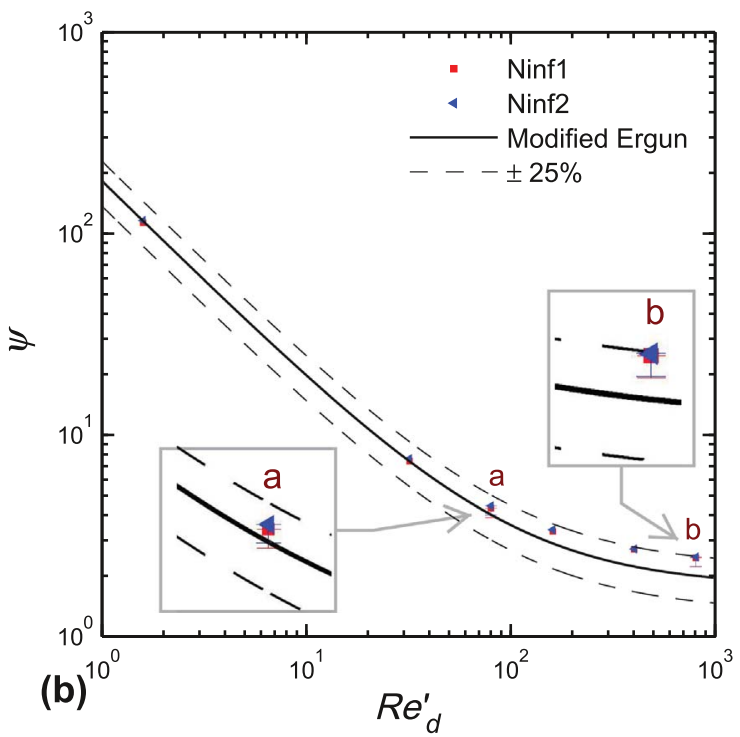

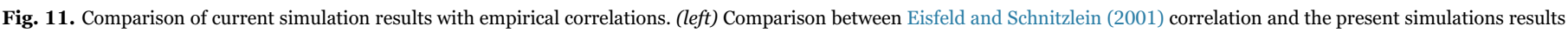

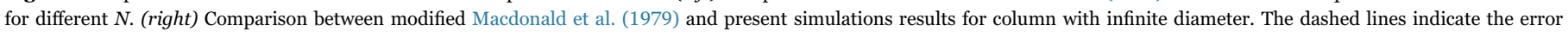
margin of $34 \%$ and $25 \%$ respectively. 
$B_{w, D N S}=2.2752-1.216 e^{-0.1738 N(1-\varepsilon)}$

$A_{D N S}=180 A_{w, D N S}$

$B_{D N S}=A_{w, D N S} B_{w, D N S}$

Fig. 12 shows that Eqs. (25) to 28? fit well the numerically obtained $A$ and $B$ for individual packing and the average deviation is only $\sim 2 \%$. Please note that, in this fitting, to estimate $N \rightarrow \infty$ for both Ninf 1 and Ninf 2 columns, $N=100$ is considered. The above form of $A$ and $B$ is partially motivated from Eisfeld and Schnitzlein (2001) correlation and when $N \rightarrow \infty$ it approach to $A_{D N S}=180$ and $B_{D N S}=2.27$. For this range $R e_{d}$, we found that the value of $B$ is higher than both Ergun and modified Ergun correlation while the $A=180$ is also found in both Carman equation and modified Ergun correlation (Macdonald et al., 1979). Most of the experimental studies available in the literature have concentrated on moderate to high Reynolds number. Presumably to achieve a better fit at higher $R e_{d}$, the accuracy is sacrificed in the lower range of Reynolds number and as a result in their correlation different values of $B$ appears. This statement can be justified by the experimental study by Dukhan et al. (2014). They studied the pressure drop through a porous medium made by metal foam where they have tried to capture accurately the Darcy to Forchheimer regime flow transition. They concluded that, for flow through porous media, $f$ vs. $R e_{d}$ curve change its slope (i.e. $B$ ) from the low to moderate to high Reynolds number and fitting the whole range of data by a single line may lead to large error. Finally, for their system, they proposed non-dimensional pressure drop correlation using a piecewise linear function. Beside this, in our case the grid independency test suggests that, at high Reynolds number the present grid resolution over-predicts the pressure drop by $\sim 10 \%$ as compared to infinitesimal grid size. Which is also contributed in the deviation between numerically obtained value of $B$ compared to experiments.

\subsubsection{Velocity profile}

Another important characteristic for the flow through packed bed is its velocity distribution. The averaged velocity field and velocity distribution can be used to study flow channeling that has a significant impact on both heat and mass transfer in packed beds. In Fig. 13 the averaged axial velocity profile over non-dimensional wall distance is shown. In this plot, the azimuthal-averaged interstitial velocity at each cross-section of the column is averaged along the length of the column. It can clearly be seen that the velocity profile follows the trend of the radial porosity profile, and as expected at places of low porosity high velocities are observed. Note that at large column diameters, flow

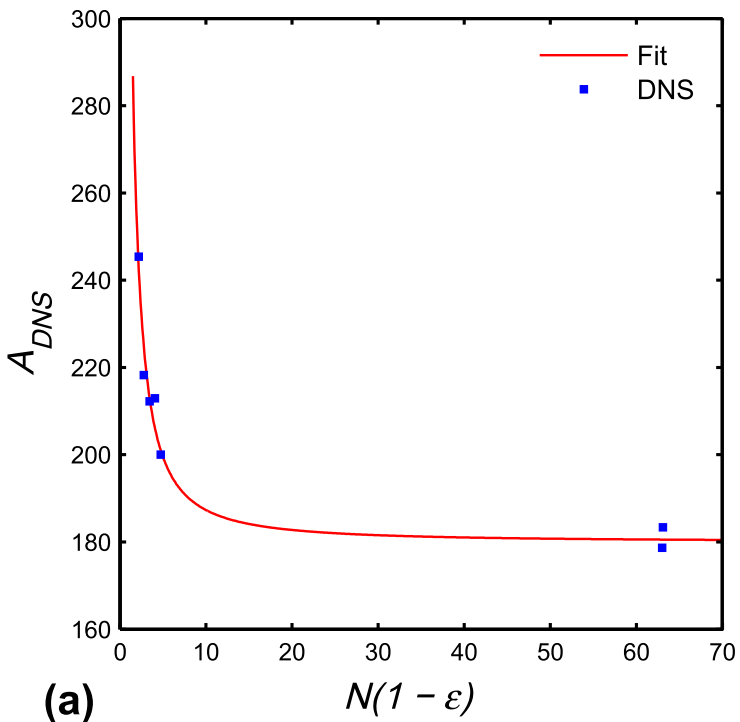

channeling only occurs near the wall and a single peak in the velocity profile is observed. For slender columns several peaks are found and for $N=4$, significant channeling occurs at the center of the column.

In Fig. 14 the axial velocity contours at the mid-plane of the N6 column are shown for $R e_{d}=1$ and $R e_{d}=500$. For the latter case, a large negative value of the axial-velocity indicates a comparatively strong local back-flow. For all the cases, the flow remains almost steady up to $R e_{d}=50$. For higher $R e_{d}$ the flow becomes unsteady, however in these cases the amplitude of the velocity and pressure fluctuations remains small $(\sim 1-2 \%)$. The high solid fraction suppresses these fluctuations.

\subsection{Heat transfer}

The wall-to-bed heat transfer rates only have been calculated for the $N 4$ to $N 8$ columns with Reynolds numbers varying from $R e_{d}=1$ to 500 . The column wall is fixed at a constant temperature ( $400 \mathrm{~K})$, which is higher than the fluid inlet temperature $(300 \mathrm{~K})$. The wall in the inletsection has the same temperature as the fluid at the inlet, to prevent any heat transfer between the column wall and fluid in the inlet section. As the fluid Prandtl number is chosen as unity, the thickness of the thermal and momentum boundary layers at the solid surfaces are the same and the same spatial resolution for solving the flow and heat equations is sufficient. If the radiative heat transfer is neglected, the wall-to-bed heat transfer occurs mainly by three different mechanisms, i.e. (i) direct conduction through the wall-particle contact points, (ii) conduction through the very thin layer of stagnant fluid between the wall and the particles near the contact point, and (iii) convective heat transfer from the wall to the flowing fluid. For macroscopic modeling of heat transfer in a porous medium, the type of thermal boundary condition influences the effective wall-to-bed heat transfer coefficient (Alazmi and Vafai, 2002). For a constant heat flux boundary condition at the column wall, different heat flux partitioning techniques have been proposed in the literature, where the total heat flux is divided into two parts; a heat flux to the porous matrix and a heat flux to the fluid. However, for the case of a constant wall temperature boundary condition, the contact area between the solid particle and wall is important. In reality the particle-particle and particle-wall contact creates a complex solid matrix through which the heat transfer cannot be neglected as generally conductivity of the solid is higher than of the fluid. The particle-particle and particle-wall very small contact area are difficult to resolve fully; especially the unstructured mesh generation involves quite a lot challenges. To account for this phenomenon in an accurate manner, Dixon et al. (2012) proposed creating solid bridges

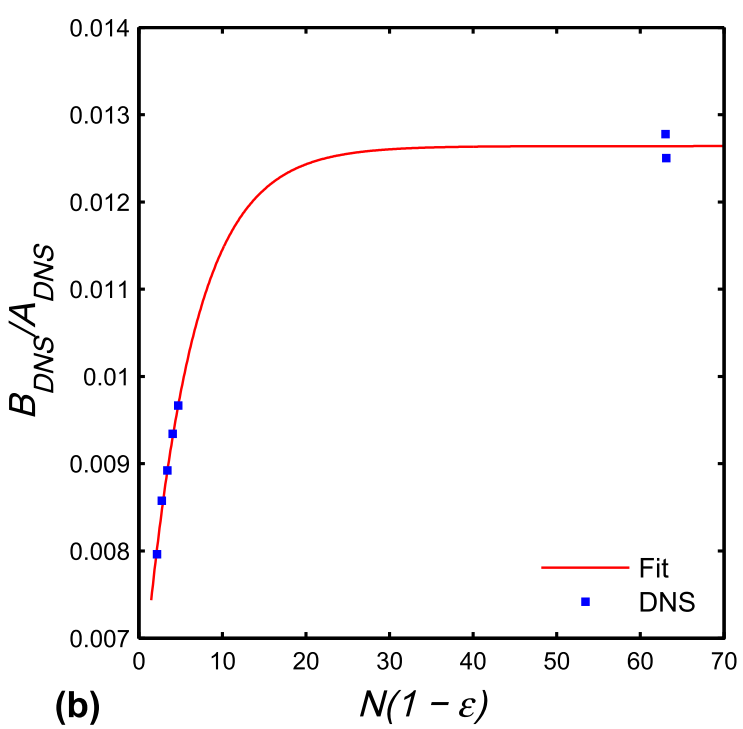

Fig. 12. Coefficient $A$ and $B$ of Ergun-type equation, obtained from DNS simulation with column-to-particle diameter. 

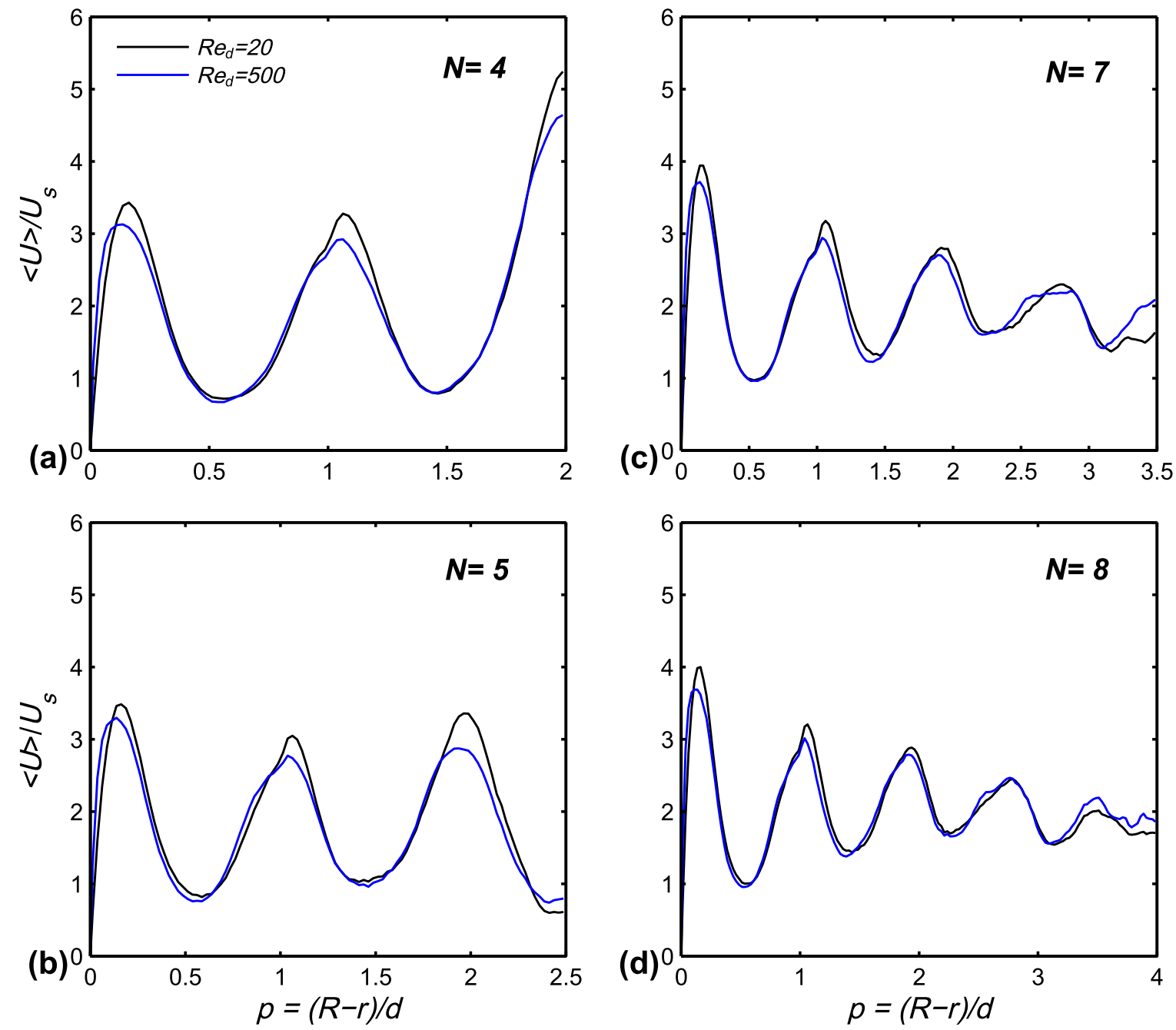

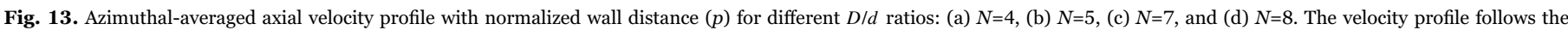
trend of the averaged radial porosity profile, and at the place of low porosity high velocities are observed.

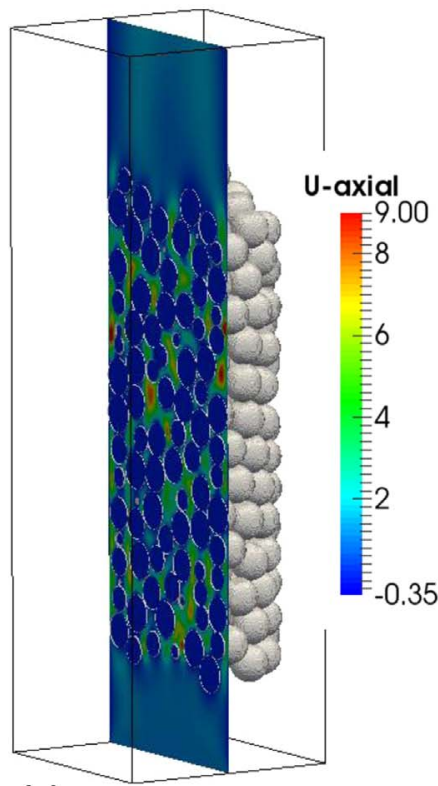

(a)

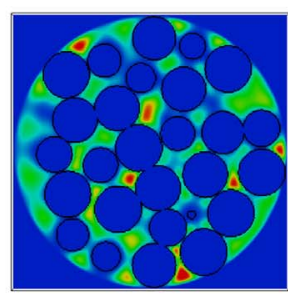

(a)

(b)

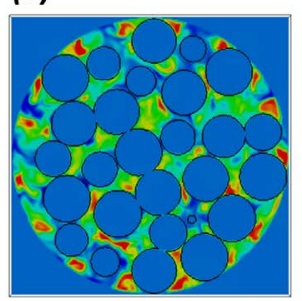

(b)

Fig. 14. Snapshot of axial velocity contours for $N=6$ column at the longitudinal and transverse cross-section of the packing: (a) $R e_{d}=1$, and (b) $R e_{d}=500$. 
between the contacting particles and the wall at the particle-wall contact point. Subsequently, they used an effective stagnant thermal conductivity of these bridges. Analytically this effective thermal conductivity is calculated based on the size of the bridge, the volume and conductivity of the solid and the fluid in the bridge. However, at moderate and high Reynolds number flows, the use of such bridges may deviate the flow field from reality. For the present case, i.e. low and moderate Reynolds number flows having a low solid conductivity, we resolve the conduction at the particle-particle and particle-wall contact area and the present spatial resolution provides a reasonable grid independent solution (see Appendix A).

\subsubsection{Temperature profile}

Fig. 15 shows the temperature contours for the mid-section of the $N 4$ and $N 8$ columns with varying Reynolds number $\left(R e_{d}\right)$. At very low
Reynolds number, the heat transfer is mainly governed by conduction and for the case of a fixed wall temperature the bed almost reaches the cylindrical wall temperature. As we increase the $R e_{d}$, the "macroscopic" thermal boundary layer starts forming at the column wall. The macroscopic boundary layer thickness deceases with increasing Reynolds number. For very slender columns the boundary layers of opposite walls tend to overlap and create a homogeneous temperature variation. Fig. 16 shows the azimuthal-averaged solid and fluid temperature profile with non-dimensional wall distance at two particular cross-sections $\left(X_{1}\right.$ and $\left.X_{2}\right)$ for $N 4$ and $N 8$ columns, and for $R e_{d}=20$ and 500. The cross-sections $X_{1}$ and $X_{2}$ ) are at, respectively, $5 d$ and $12.5 d$ height from the inlet of the column as shown in Fig. 16-b and $\mathrm{d}$. The expansion of the macroscopic boundary layer thickness is clearly visible, which decreases with increase in $R e_{d}$. The upstream temperature is higher than the downstream temperature due to the heat

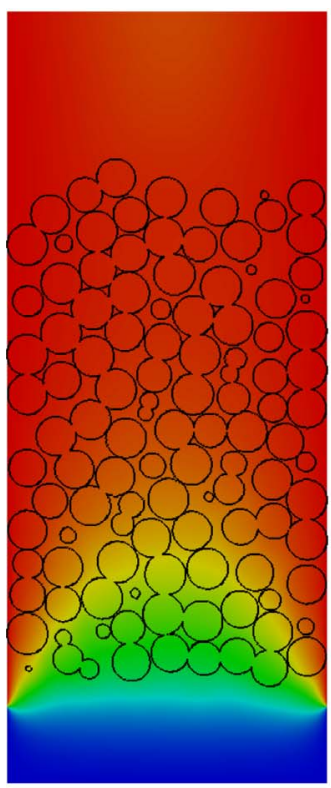

$\operatorname{Re}_{d}=1$



$\boldsymbol{R} e_{d}=\mathbf{2 0}$

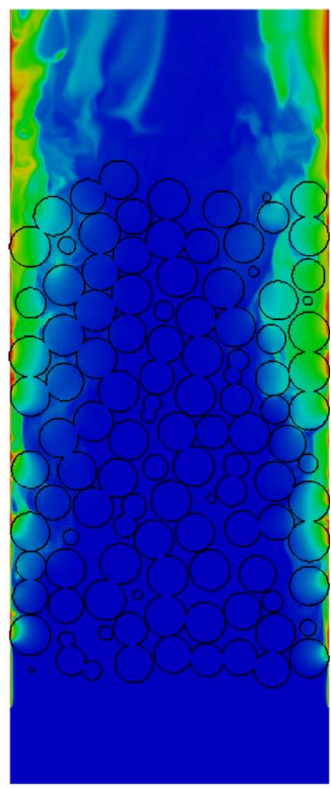

$\operatorname{Re}_{d}=100$

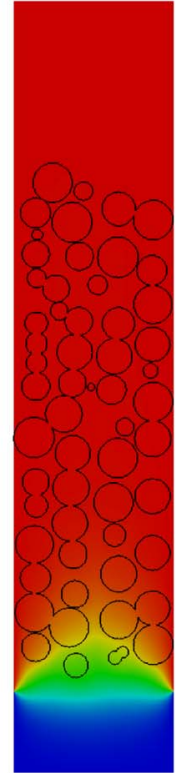

$R e_{d}=1$

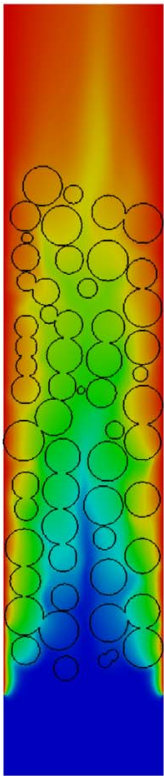

$\boldsymbol{R e}_{d}=\mathbf{2 0}$

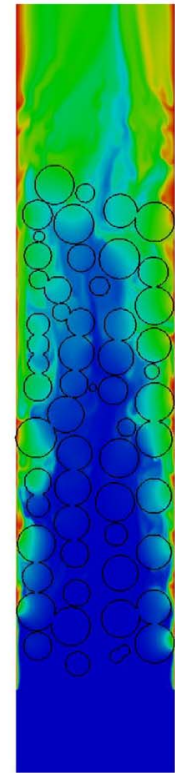

$\boldsymbol{R e}_{d}=\mathbf{1 0 0}$
$\mathrm{T}$

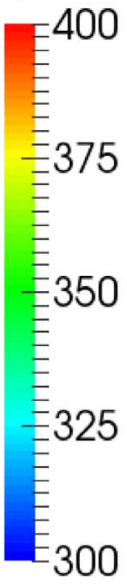

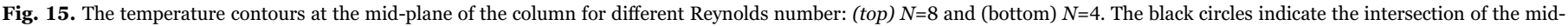
plane and the solid particles. 


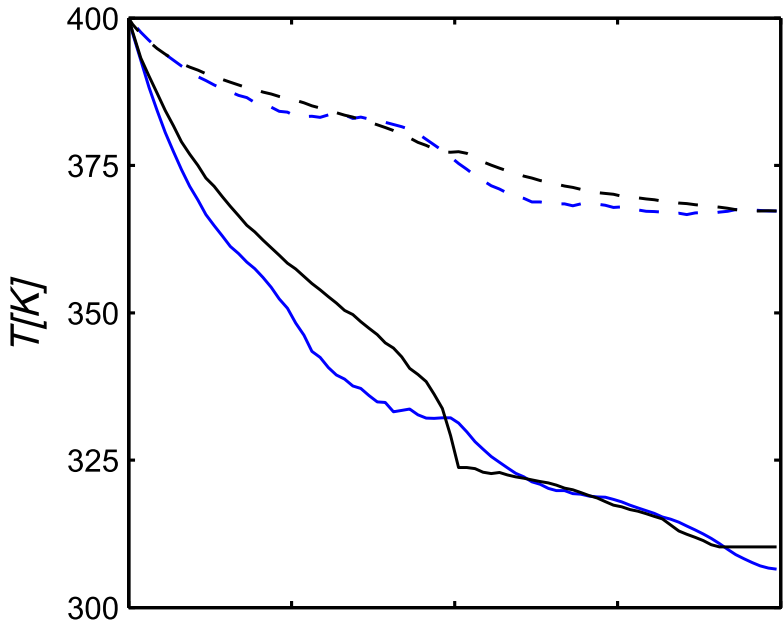

(a)

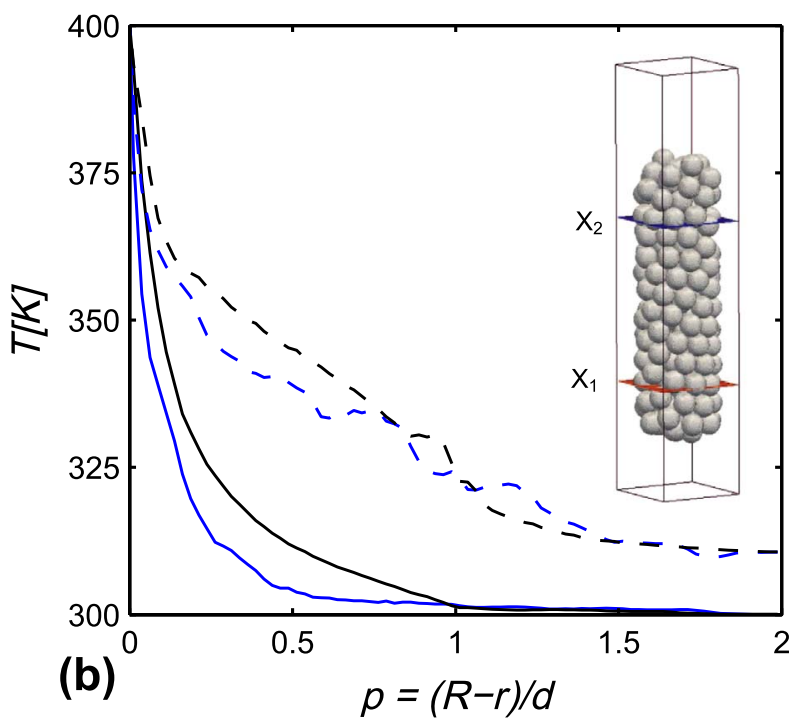

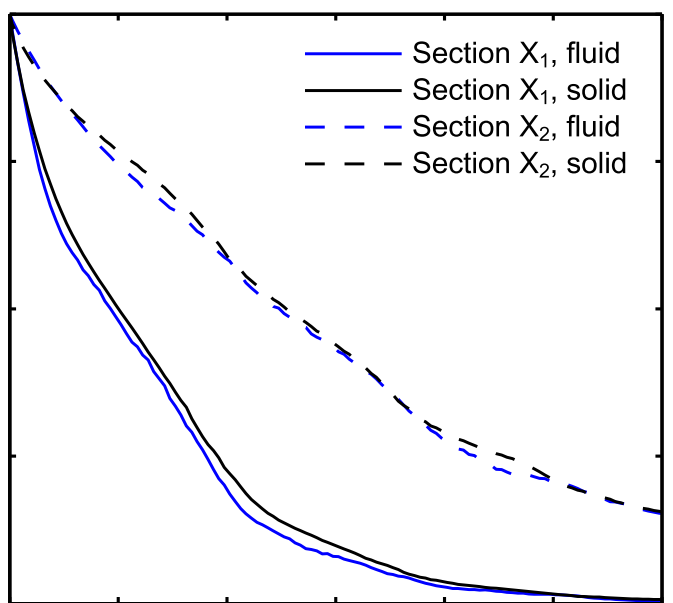

(c)

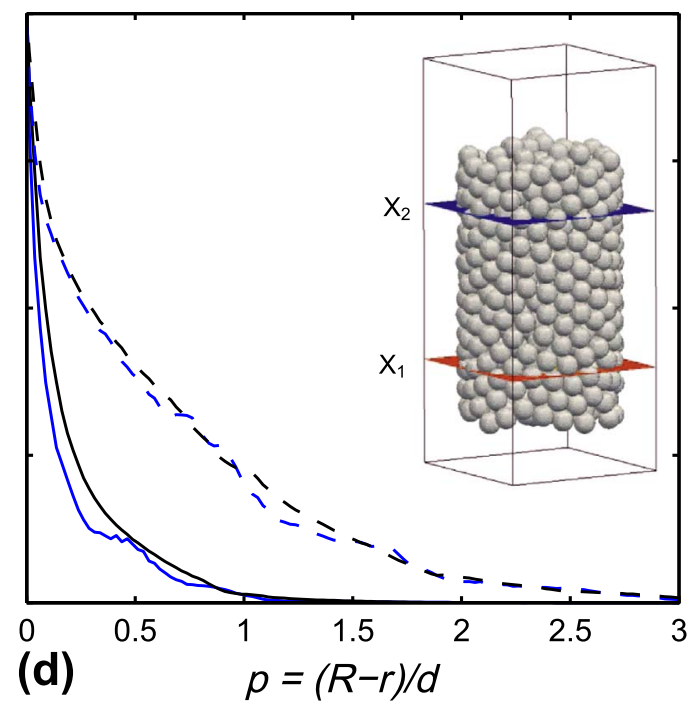

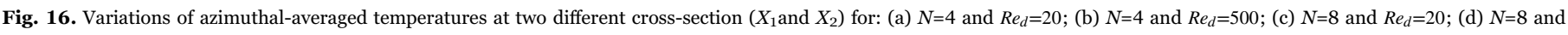
$R e_{d}=500$.

addition to the system. The difference between the solid and fluid temperature is small irrespective of the Reynolds number as the conductivity ratios are small.

\subsubsection{Local wall-to-bed heat transfer coefficient}

The local wall-to-bed heat transfer coefficient was calculated at each cross-section of the column, along the axial direction $(m=x / d)$ using the following equation:

$h_{l}=\frac{\dot{Q}_{\text {wall }, l}}{\Delta T}$

where $\dot{Q}_{\text {wall, }}$ is the total heat flux coming from the cylindrical wall to the bed at the particular cross-section, and $\Delta T$ is the temperature difference between the cylindrical wall $\left(T_{\text {wall }}\right)$ and the cup-mixing or bulk temperature ( $T_{\text {cup-avg }}$ ) of the fluid at that section,

$\Delta T=T_{\text {wall }}-T_{\text {cup }- \text { avg }}$

$T_{\text {cup-avg }}=\frac{\int_{A_{f}} u_{a} T d A_{f}}{\int_{A_{f}} T d A_{f}}$

where, $u_{a}$ represents the axial interstitial velocity and $A_{f}$ is the total area of fluid at a section of the column. The heat transfer coefficient can also be expressed in a non-dimensional form, i.e. as a local Nusselt number $\left(N u_{d, l}\right)$, which is defined as:

$N u_{d, l}=\frac{h_{l} d}{k_{f}}$

Results for the local Nusselt number $\left(N u_{d, l}\right)$ are shown in Fig. 17. At very low Reynolds number, the main mode of heat transfer is conduction and the total heat transfer rates are predominantly governed by the conductivity of the bed. The solid spheres have a comparatively higher thermal conductivity. Hence, particles that are in contact with the column wall lead to an increase in the heat transfer rate. As a result, several spikes in the heat transfer coefficient are observed in Fig. 17-a and -e at the locations of the particle-wall contact points. For the columns of larger diameter (Fig. 17-e), the thickness of these spikes is increased due to the larger number of particles (i.e. larger contact area) that are in contact with the wall. Please recall that spherical particles are placed at a dimensionless height of $\sim 3<m<\sim 15$ of the column, and as a result when $m>\sim 15$, the heat transfer drops. At higher Reynolds numbers, the heat transfer is governed by convection. The vigorous flow around the solid particles augments the heat transfer. For moderate and high $R e_{d}$, the fluctuations of the $N u_{d, l}$ along the axial direction are mainly due to fluctuations in interstitial velocity along the axis (caused by the variation in the axial porosity profile). The magnitude of theses fluctuations is 

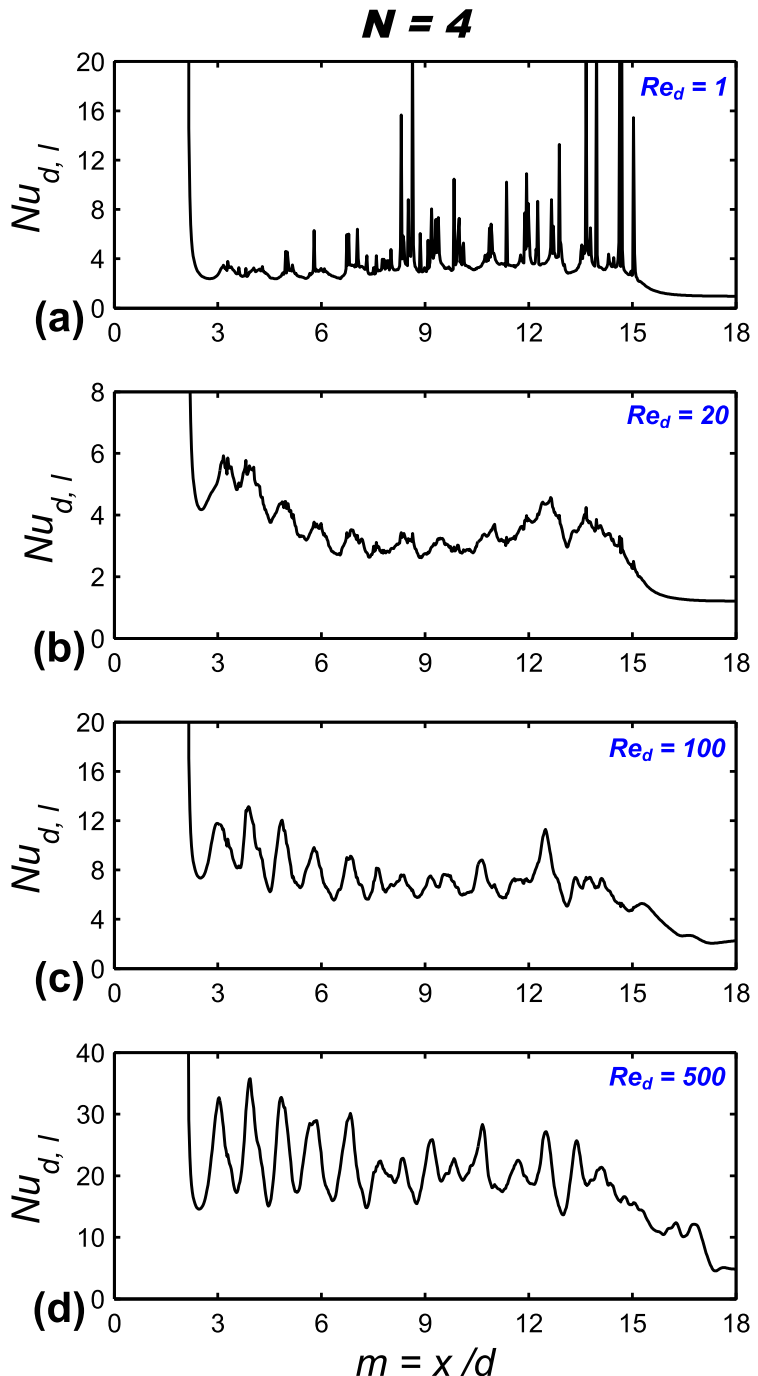
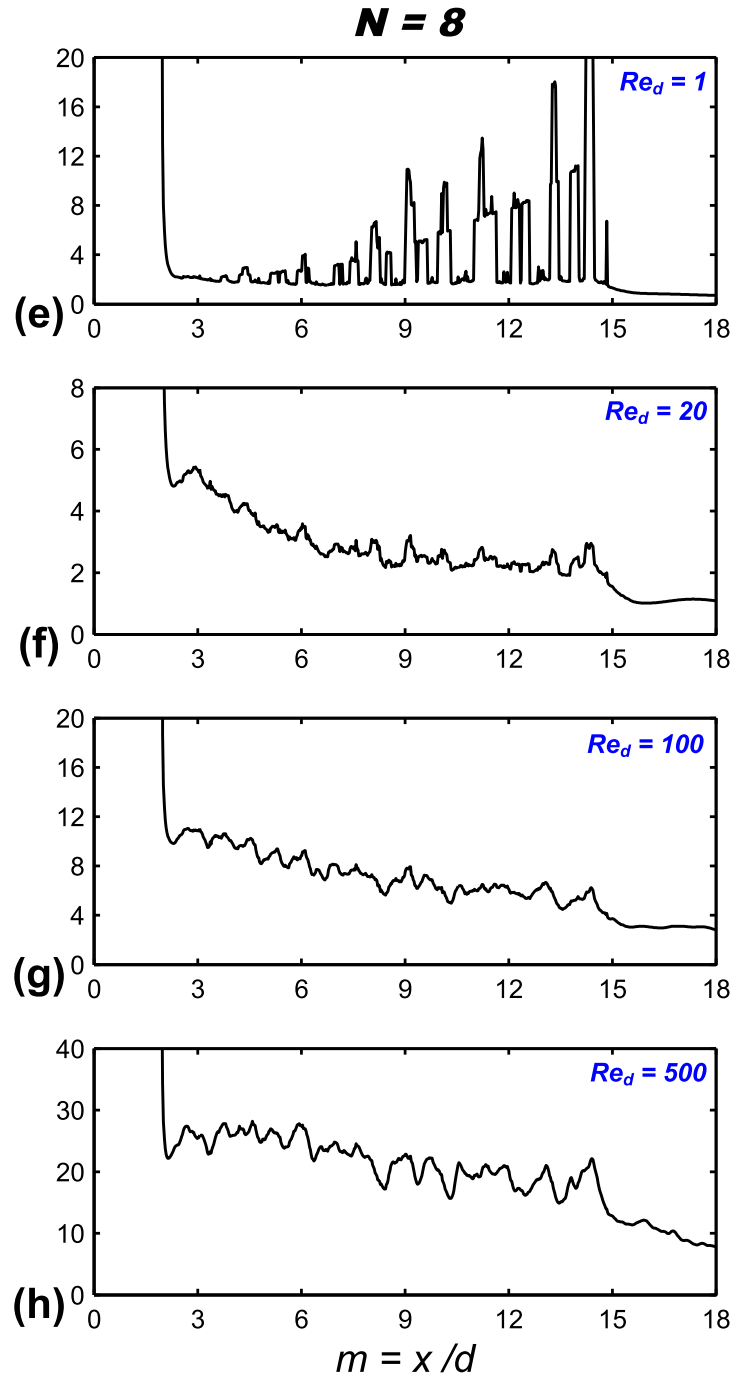

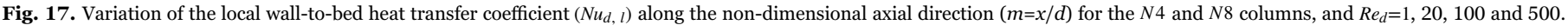

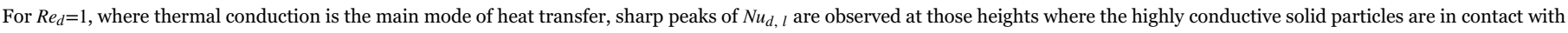
the wall. For higher $R e_{d}$, the fluctuations of $N u_{d, l}$ are due to fluctuations in the porosity distribution and back-flow.

higher for the $N 4$ column compared to the $N 8$ column, as variations in the axial porosity profile are also higher for the $N 4$ column (see Fig. 8). For the same packing structure, the amplitude of these fluctuations increases with increase in $R e_{d}$, due to the increase in local back-flow.

\subsubsection{Overall wall-to-bed heat transfer coefficient}

To calculate the overall wall-to-bed heat transfer coefficient, we have chosen two column cross-sections, at the two ends of the packings (Fig. 5-a). The down-stream bulk temperature is refer as $T_{A}$ and upstream as $T_{B}$. The wall-to-bed overall heat transfer coefficient in the present case is defined as:

$h=\frac{\dot{Q}_{\text {wall }}}{\Delta T_{L M T D}}$

where $\dot{Q}_{\text {wall }}$ is the total heat flux coming from the cylindrical wall to the bed and $\Delta T_{L M T D}$ is the logarithmic mean temperature, defined as:

$\Delta T_{L M T D}=\frac{\Delta T_{B}-\Delta T_{A}}{\ln \left(\Delta T_{B} / \Delta T_{A}\right)}$

$\Delta T_{A}=T_{\text {wall }}-T_{A}$

$\Delta T_{B}=T_{\text {wall }}-T_{B}$

Similar to the hydrodynamics study, we use the particle diameter (d) to define both the characteristic Reynolds number $\left(R e_{d}\right)$, and the non-dimensional heat transfer coefficient i.e. Nusselt number.:

$N u_{d}=\frac{h d}{k_{f}}$

Several experimental correlations for heat transfer coefficients are available in the literature (Leva, 1947; Colburn, 1931; Yagi and Wakao, 1959; Chu and Storrow, 1952). At low Reynolds number it is difficult to accurately measure the heat transfer coefficients, and as a result most of the experimental studies focus on moderate and high $R e_{d}$ flows. In most of the literature the heat transfer coefficient is proposed in the form of $N u=p R e^{q}$. Experimentally, it is found that $q \sim\left[\begin{array}{ll}0.75 & 0.9\end{array}\right]$ for moderate and high $R e_{\boldsymbol{d}}$. The first work of heat transfer through packed bed was performed by Colburn (1931), The overall heat transfer coefficient was correlated in terms of $R e_{d}$ and $N$, where high $R e_{d}$ cases were considered. On the other hand, Yagi and Wakao (1959) performed experiments in the range of $1 \leq R e_{d} \leq 2000$ and found that the column-to-particle diameter ratio has a negligible effect on $\mathrm{Nu}$. They also checked the effect of solids conductivity on the overall heat transfer and at moderate $R e_{d}$ the main mechanism of heat transfer is convection. They also observed no significant effect of the solids conductivity on the overall heat transfer coefficient. They proposed the following correlation for the heat transfer coefficient: 


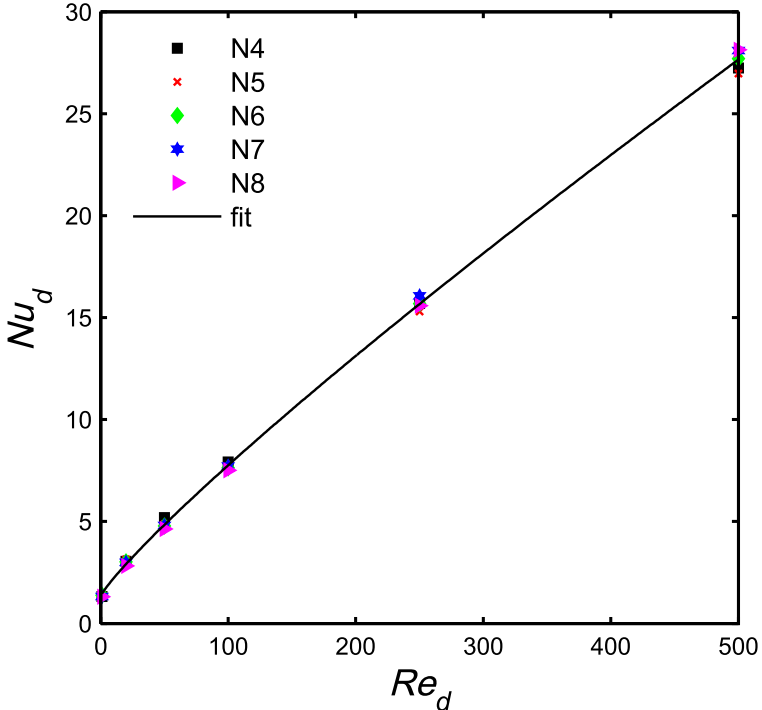

Fig. 18. The non-dimensional heat transfer coefficient $\left(N u_{d}\right)$ with Reynolds number $\left(R e_{d}\right)$ for different column-to-particle diameter ratios ( $N=4$ to 8$)$.

$N u_{d, Y a g i}= \begin{cases}0.6 \operatorname{Pr}^{1 / 3} \operatorname{Re}_{d}^{1 / 2}, & 1 \leq \operatorname{Re}_{d} \leq 40 \\ 0.2 \operatorname{Pr}^{1 / 3} \operatorname{Re}_{d}^{0.8}, & 40 \leq \operatorname{Re}_{d} \leq 20000\end{cases}$

Leva (1947) performed similar experimental studies for packed beds of spheres where they varied $N$ from 6.67 to 20 and $R e_{d}$ from $\sim 200$ to 3000. Air $(\operatorname{Pr} \sim 0.74)$ was used as a working fluid, and glass and clay particles were used as solid packing. They also considered the column-to-particle diameter ratio $(N)$ in their correlation:

$N u_{d, \text { Liva }}=0.813 \frac{e^{-6 / N}}{N} R e_{d}^{0.9}$

By closely looking into Eq. (39) we can find that for $N$ varying from 4 to 8 , the quantity $0.813 \times \frac{e^{-6 / N}}{N}$ varies from 0.045 to 0.048 , i.e. the deviation is in the limit of experimental accuracy and can be neglected. In our case too we found a variation in heat transfer coefficient of $2 \%$ from the average value for different $N$, which we subsequently neglected. In Fig. 18 and Table 5 the numerically obtained $N u_{\boldsymbol{d}}$ is shown. As forced convection is the main mechanism for heat transfer, with increase in Reylonds number the heat transfer rate is also increase. Please note that in our simulations we have chosen $\operatorname{Pr}=1$. The following curve-fit equation is proposed:

$N u_{d}=1.351+0.1124 \operatorname{Re}_{d}^{0.878} \operatorname{Pr}^{1 / 3}$

The first term on the right hand side of Eq. (40) represents the heat transfer for very slow flow when conduction is important and $N u_{d}$ is independent of Pr. In most of the experimental studies this term is generally neglected due to difficulties to measure heat transfer at low Reynolds number flow. To incorporate the effect of fluid properties we multiply the Reynolds number term with $\mathrm{Pr}^{1 / 3}$. This dependency of $N u_{d}$ on $\mathrm{Pr}$ can be justified by boundary layer theory and is well reported in the literature. Fig. 19 shows a comparison of our current numerical results with the correlation by Yagi and Wakao (1959). It shows that

Table 5

The numerically obtained $N u_{d}$ for different $R e_{d}$ and $N$.

\begin{tabular}{lllllll}
\hline & $R e_{d}=1$ & $R e_{d}=20$ & $R e_{d}=50$ & $R e_{d}=100$ & $R e_{d}=250$ & $R e_{d}=500$ \\
\hline$N=4$ & 1.325 & 3.044 & 5.192 & 7.918 & 15.700 & 27.246 \\
$N=5$ & 1.426 & 3.140 & 4.873 & 7.634 & 15.303 & 26.971 \\
$N=6$ & 1.379 & 3.021 & 4.787 & 7.637 & 15.684 & 27.694 \\
$N=7$ & 1.317 & 2.999 & 4.808 & 7.726 & 16.066 & 28.096 \\
$N=8$ & 1.306 & 2.823 & 4.626 & 7.513 & 15.589 & 28.128 \\
Curve-fit (Eq.(40)) & 1.4634 & 2.9099 & 4.8354 & 7.7537 & 15.6623 & 27.6490 \\
\hline
\end{tabular}

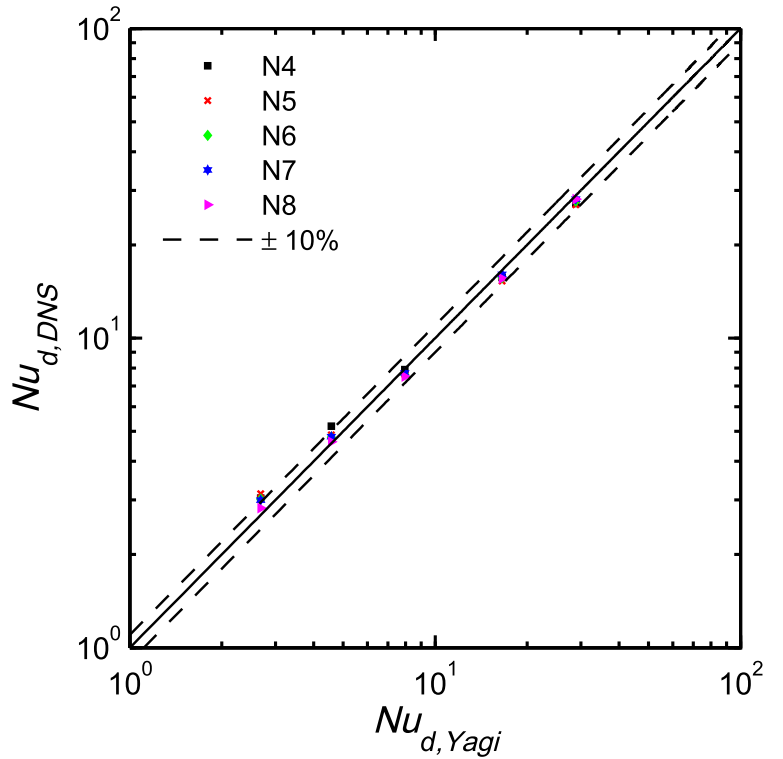

Fig. 19. Comparison of numerically obtained overall heat transfer coefficient with experimental correlation by Yagi and Wakao (1959). The dashed lines indicate an error margin of $10 \%$.

except for very low $R e_{d}$ all the results are within an error margin of $10 \%$.

\subsubsection{Effect of solid-to-fluid conductivity ratio}

In this conjugate heat transfer analysis it is interesting to study the effect of solid to fluid conductivity ratio on the overall heat transfer coefficient. In the present case $k_{s} / k_{f}=10$ is considered, however for $N 6$ column and $R e_{d}=1,50$, and 500 we have considered $k_{s} / k_{f}=1$ and 100 to check the effect of solid conductivity on the overall heat transfer. The values of $N u_{d}$ for all these cases are shown in Table 7 . As expected the increase in solid conductivity increases the overall heat transfer rate, but this increase is relatively very small, in particular at high Reynolds numbers. For very high solid to fluid conductivity ratio this dependency flattens off. Similar observations were reported by Yagi and Wakao (1959) in their experimental work. When we specify a constant wall temperature boundary condition at the column wall, the amount of heat transferred to the bed depends on the combined effect of the particle conductivity and the contact area between the particle and wall. As the particle-wall contact area is very small, the amount of heat coming directly through the solid conduction is small and consequently the effect of solid conductivity is also small.

\section{Conclusions}

In the present paper an in-house immersed boundary method based finite volume code has been used to simulate flow and heat transfer through slender fixed bed reactors packed with spherical particles. Both the cylinder wall and the particle surfaces are resolved by an immersed boundary method in a Cartesian computational domain. As a result the current numerical technique does not require any challenging mesh generation process and particle-particle contact point treatment. A discrete element method has been used to generate random packing in a cylindrical container. A new methodology is proposed to calculate axial and radial porosity profile.

The column-to-particle diameter ratio is varied from 4 to 8 , and the particle Reynolds number from 1 to 500 . Also two separate cases have been considered where ideally $N \rightarrow \infty$. The overall bed porosity, aswell-as the radial porosity profile (averaged) obtained from DEM simulation has been compared with the existing literature results, and an excellent agreement is found. The non-dimensional pressure drop and the overall heat transfer coefficient has been compared with 
Table 6

Grid convergence study for a section of the packings: comparison of calculated $f$ and relative error for different grid resolutions.

\begin{tabular}{|c|c|c|c|c|c|}
\hline Cases & $\Delta x=\Delta y=\Delta z(m)$ & $f$ & $\%$ - difference & $N u_{d}$ & $\%$ - difference \\
\hline \multirow[t]{4}{*}{$R e_{d}=50$} & G20: 0.0015 & 561.98 & 27.29 & 3.99 & 28.44 \\
\hline & G40: 0.00075 & 445.39 & 8.25 & 3.0817 & 7.36 \\
\hline & G80: 0.000375 & 417.03 & 2.01 & 2.8831 & 0.98 \\
\hline & Extrapolated: 0 & 408.63 & 0 & 2.8549 & 0 \\
\hline \multirow{4}{*}{$R e_{d}=500$} & G20: 0.0015 & 3162.69 & 31.61 & 16.256 & 18.63 \\
\hline & G40: 0.00075 & 2404.19 & 10.03 & 14.726 & 10.17 \\
\hline & G80: 0.000375 & 2218.96 & 2.52 & 13.973 & 5.33 \\
\hline & Extrapolated: 0 & 2163.10 & 0 & 13.228 & 0 \\
\hline
\end{tabular}

Table 7

Effect of solid to fluid conductivity ratio on over-all non-dimensional heat transfer coefficient $\left(N u_{d}\right)$ for $N 6$ column.

\begin{tabular}{lccc}
\hline$k_{s} / k_{f} \downarrow$ & $R e_{d}=1$ & $R e_{d}=50$ & $R e_{d}=500$ \\
\hline 1 & 7.74 & 25.62 & 160.71 \\
10 & 8.27 & 28.72 & 166.71 \\
100 & 9.48 & 29.87 & 167.68 \\
\hline
\end{tabular}

experimental correlations and also a good match has been observed.

The effect of the cylinder wall on the pressure drop has been studied. It is found that at low column-to-particle diameter ratios the wall effect is important for pressure drop. However, the column-toparticle diameter ratio has an insignificant effect on the overall heat transfer coefficient. Similarly, it is found that the solid conductivity also has a very small effect on the overall heat transfer rate. Similar behavior was previously reported in several experimental studies. Based on the current numerical results, finally we have proposed correlations for the pressure drop and the overall heat transfer coefficient.

In the present study, we have only considered monodisperse spherical particle without any reaction or heat generation. It is interesting to study the effect of particle size (i.e. polydispersity), shape (i.e. sphericity) on overall flow and heat transfer results.

A proper grid resolution at the particle-particle contact point is very important and any geometrical manipulations at the particle-particle contact points may leads to large errors. From grid refinement tests, it is found that the present fully resolved numerical results are reasonably grid independent. However, use of a sub-grid level modeling approach or grid adaptation, only at the particle-particle contact area, will reduce the mesh count for grid independence results, and in this direction, further investigation is required.

\section{Acknowledgments}

We thank SURF SARA (www.surfsara.nl) and NWO for the support in using the Cartesius supercomputer. We would also like to thank Prof. Stefan Pirker, Johannes Kepler University Linz for kindly providing us the DEM code LIGGGHTS.

This paper is an extension of a conference paper that was presented at the Eleventh International Conference on CFD in the Minerals and Process Industries (CFD2015), and was nominated for submission to Chemical Engineering Science based on its designation as a highquality paper of relevance to chemical engineering.

\section{Appendix A. Grid interdependence test}

For the current fully resolved IBM based numerical techniques the grid resolution should be fine enough to fully represent the solid immersed boundary in the non-conformal Cartesian grids. For a spherical or cylindrical body at infinite domain, we have verified that 20 grid cells across the diameter of a sphere is more than sufficient to achieve grid independent results for both flow and heat transfer (Das et al., 2016a, 2016b). However, for the current problem at hand, the very small gap in between two contacting spheres needs special attention. In the literature, where the unstructured mesh has been used to simulate this complex domain either this gap has been fused (by increasing the diameter of the spheres or creating cylindrical bridges) or this gap has been increased (by reducing the diameter of the sphere or capping the sphere). As a result, for those studies grid independent results are easily achieved. However, those results can largely differ from the actual system and would require ad-hoc tuning of the particle diameter and/or porosity (Boccardo et al., 2015).

To check the accuracy of the current method, we have taken a small section of a large column and performed simulations with varying grids. In Fig. 5-c the computational domain used for grid independent test is shown. All the side walls are specified as free-slip boundaries with constant wall temperature. Simulations are performed for two different Reynolds numbers, $R e_{d}=50$ and $R e_{d}=500$ and three different grids, $G 20$ (20 grid cells across the diameter), $G 40$, and $G 80$. The nondimensional friction factor $(f)$ and Nusselt number $\left(N u_{d}\right)$ for different grid resolution are shown in Table 6 . The value of $f$ and $N u_{d}$ for infinite grid resolution $(\Delta x \rightarrow 0)$ is estimated by extrapolation of the results for the performed simulations. It is found that for both $R e=50$ and $R e=500$, the $G 80$ grid provides grid independent results. However, all the simulations presented in this paper were done with $G 40$ grids. For the $N=8$ column the total cell count is already as high as $\sim 80$ million and using a $G 80$ grid would lead to a grid count of $\sim 640$ million, which is very computationally expensive. It is for this reason that we have done all simulations with the $G 40$ grid. It is worth to mention that we have also checked the effect of grid resolution for creeping flow cases and it is observed that under those conditions the $G 20$ grid is sufficient to have grid independent results. Hence, it can be confirmed that resolving the boundary layer near the particle-particle intersection for inertial flows is crucial.

\section{References}

Alazmi, B., Vafai, K., 2002. Constant wall heat flux boundary conditions in porous media under local thermal non-equilibrium conditions. Int. J. Heat. Mass Transf. 45 (15), 3071-3087.

Atmakidis, T., Kenig, E.Y., 2009. CFD-based analysis of the wall effect on the pressure drop in packed beds with moderate tube/particle diameter ratios in the laminar flow regime. Chem. Eng. J. 155 (1), 404-410.

Bai, H., Theuerkauf, J., Gillis, P.A., Witt, P.M., 2009. A coupled DEM and CFD simulation of flow field and pressure drop in fixed bed reactor with randomly packed catalyst particles. Ind. Eng. Chem. Res. 48 (8), 4060-4074.

Boccardo, G., Augier, F., Haroun, Y., Ferré, D., Marchisio, D.L., 2015. Validation of a novel open-source work-flow for the simulation of packed-bed reactors. Chem. Eng. J. 279, 809-820.

Chu, Y., Storrow, J.A., 1952. Heat transfer to air flowing through packed tubes. Chem. Eng. Sci. 1 (5), 230-237.

Colburn, A.P., 1931. Heat transfer and pressure drop in empty, baffled, and packed tubes1. Ind. Eng. Chem. 23 (8), 910-913.

Džiugys, A., Peters, B., 2001. An approach to simulate the motion of spherical and nonspherical fuel particles in combustion chambers. Granul. Matter 3 (4), 231-266.

Das, S., Deen, N.G., Kuipers, J.A.M., 2016a. Immersed Boundary Method (IBM) based Direct Numerical Simulation of open-cell solid foams: hydrodynamics. AIChE J. doi:10.1002/aic.15487

Das, S., Deen, N.G., Kuipers, J.A.M., 2016b. Direct numerical simulation for flow and 
heat transfer through random open-cell solid foams: Development of an IBM based CFD model, Catalysis Today, http://dx.doi.org/10.1016/j.cattod.2016.03.048.

de Klerk, A., 2003. Voidage variation in packed beds at small column to particle diameter ratio. AIChE J. 49 (8), 2022-2029.

Dixon, A.G., Nijemeisland, M., 2001. CFD as a design tool for fixed-bed reactors. Ind. Eng. Chem. Res. 40 (23), 5246-5254.

Dixon, A.G., Walls, G., Stanness, H., Nijemeisland, M., Stitt, E.H., 2012. Experimental validation of high Reynolds number CFD simulations of heat transfer in a pilot-scale fixed bed tube. Chem. Eng. J. 200, 344-356.

Dixon, A.G., Nijemeisland, M., Stitt, E.H., 2013. Systematic mesh development for 3D CFD simulation of fixed beds: contact points study. Comput. Chem. Eng. 48, 135-153.

Dixon, A.G., 1988. Correlations for wall and particle shape effects on fixed bed bulk voidage. Can. J. Chem. Eng. 66 (5), 705-708.

Dixon, A.G., 2012. Fixed bed catalytic reactor modelling-the radial heat transfer problem. Can. J. Chem. Eng. 90 (3), 507-527.

Dukhan, N., Bağc1, Ö., Özdemir, M., 2014. Metal foam hydrodynamics: flow regimes from pre-Darcy to turbulent. Int. J. Heat. Mass Transf. 77, 114-123.

Eisfeld, B., Schnitzlein, K., 2001. The influence of confining walls on the pressure drop in packed beds. Chem. Eng. Sci. 56 (14), 4321-4329.

Eppinger, T., Seidler, K., Kraume, M., 2011. DEM-CFD simulations of fixed bed reactors with small tube to particle diameter ratios. Chem. Eng. J. 166 (1), 324-331.

Jeschar, R., 1964. Druckverlust in Mehrkornschüttungen aus Kugeln. Arch. für Das. Eisenhüttenwes. 35 (2), 91-108.

Leva, M., 1947. Heat transfer to gases through packed tubes. Ind. Eng. Chem. 39 (7), $857-862$

〈http://www.liggghts.com
Macdonald, I., El-Sayed, M., Mow, K., Dullien, F., 1979. Flow through porous media-the Ergun equation revisited. Ind. Eng. Chem. Fundam. 18 (3), 199-208.

Maier, R.S., Kroll, D., Kutsovsky, Y., Davis, H., Bernard, R.S., 1998. Simulation of flow through bead packs using the Lattice Boltzmann Method. Phys. Fluids (1994Present) 10 (1), 60-74.

Mueller, G.E., 2012. A simple method for determining sphere packed bed radial porosity. Powder Technol. 229, 90-96.

Nemec, D., Levec, J., 2005. Flow through packed bed reactors: 1. Single-phase flow. Chem. Eng. Sci. 60 (24), 6947-6957.

Niven, R.K., 2002. Physical insight into the Ergun and Wen \& Yu equations for fluid flow in packed and fluidised beds. Chem. Eng. Sci. 57 (3), 527-534.

Ookawara, S., Kuroki, M., Street, D., Ogawa, K., 2007. High-fidelity DEM-CFD modeling of packed bed reactors for process intensification. In: Proceedings of European Congress of Chemical Engineering (ECCE-6), Copenhagen, pp. 16-20.

Riefler, N., Heiland, M., Räbiger, N., Fritsching, U., 2012. Pressure loss and wall shear stress in flow through confined sphere packings. Chem. Eng. Sci. 69 (1), 129-137.

Strack, O., Cundall, P.A., 1978. The distinct element method as a tool for research in granular media. Department of Civil and Mineral Engineering. University of Minnesota.

Tabib, M.V., Johansen, S.T., Amini, S., 2013. A 3D CFD-DEM methodology for simulating industrial scale packed bed chemical looping combustion reactors. Ind Eng. Chem. Res. 52 (34), 12041-12058.

Yagi, S., Wakao, N., 1959. Heat and mass transfer from wall to fluid in packed beds. AIChE J. 5 (1), 79-85.

Zhang, W., Thompson, K.E., Reed, A.H., Beenken, L., 2006. Relationship between packing structure and porosity in fixed beds of equilateral cylindrical particles. Chem. Eng. Sci. 61 (24), 8060-8074. 